Check for updates

Cite this: Mater. Adv., 2022, 3,1472

Received 12th July 2021 Accepted 19th December 2021

DOI: 10.1039/d1ma00599e

rsc.li/materials-advances

\title{
Advances in materials and fabrication of separators in supercapacitors
}

\begin{abstract}
Sandeep Ahankari, (D)*a Dylan Lasrado ${ }^{a}$ and Ramesh Subramaniam ${ }^{b}$
Supercapacitors (SCS) have been extensively used in advanced energy applications due to their superior energy storage capacity and rapid charge-discharge rate. The significant constituents of a SC include two electrodes, an electrolyte and a separator. The integrated performance of all these constituents is necessary to enhance the energy storage ability of the device. For advanced electrochemical energy systems, the search for separator materials with higher ionic conductivity, mechanical strength, thermal stability, longer life and low cost of manufacturing is necessary. Appropriate design and fabrication of a separator improves the thermal stability, specific capacity, efficiency and life of a SC. In this review, a study on various materials that are used in the fabrication of separator membranes namely polymer, polymer-ceramic, and bio-based materials and the influence of these materials on the overall performance of the SC is presented. New trends in developing devices by integrating smart separator materials with SCs are also highlighted.
\end{abstract}

\section{Introduction}

In the last decade, the field of portable electronic systems has witnessed tremendous growth with the development and

${ }^{a}$ School of Mechanical Engineering, VIT University, Vellore, TN-632014, India. E-mail: asandeep.s@vit.ac.in

${ }^{b}$ Department of Physics, Faculty of Science, Universiti Malaya, 50603 Kuala Lumpur, Malaysia



Sandeep Ahankari
Sandeep Ahankari is working as an Associate Professor at the School of Mechanical Engineering at VIT University, Vellore, $T N$, India. He is basically a mechanical engineer, and pursued his PhD from IIT Kanpur, India, and postdoctoral research at University of Guelph, ON, Canada. His area of interest includes processing and thermomechanical characterization of bio/polymer nanocomposites, biobased materials for energy, packaging and membrane applications, functionally graded composites, etc. He has published fourteen international journal papers and more than twenty international conference papers, authored seven book chapters and have five filed patents to his credit.

application of numerous types of sensors and other flexible electronic devices. ${ }^{1,2}$ This has stimulated the need for the development of portable energy storage devices such as batteries, fuel cells and supercapacitors (SCs). Batteries have the ability to store significant amounts of energy and are able to provide the same for many applications. However, a major drawback in the use of batteries is their less power density and relatively lower shelf and cycle life. SCs, on the other hand, are energy storage devices that have properties such as specific

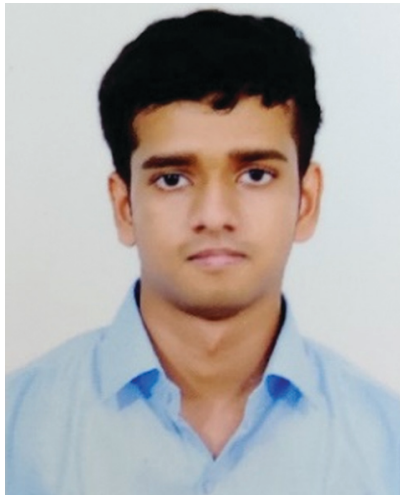

Dylan Lasrado
Dylan Lasrado is a graduate student at the School of Mechanical Engineering at VIT University, Vellore, TN, India. Recently he has worked on a project based on crystalline nanocellulose reinforced polyaniline composites, under the guidance of $\mathrm{Dr}$ Sandeep Ahankari. He published one international journal paper in 2020. He has also published a book chapter titled "Global trends in supercapacitors", published by Springer Nature, Switzerland. 
power density (0.1-100 $\left.\mathrm{kW} \mathrm{kg}^{-1}\right)$ and specific energy density (0.11-10 $\mathrm{W} \mathrm{h} \mathrm{kg}^{-1}$ ) which lie in between those of electrochemical batteries (0.01-1 $\mathrm{kW} \mathrm{kg}^{-1} ; 10-100 \mathrm{~W} \mathrm{~h} \mathrm{~kg}^{-1}$ ) and capacitors $\left(100-10^{4} \mathrm{~kW} \mathrm{~kg}^{-1} ;<0.1 \mathrm{~W} \mathrm{~h} \mathrm{~kg}^{-1}\right) .{ }^{3,4}$ SCs exhibit promising properties such as a fast charge-discharge rate within seconds, a high specific power density $\left(10 \mathrm{~kW} \mathrm{~kg}^{-1}\right)$ and a long cycle life ( $>10^{5}$ cycles). ${ }^{5-7}$ In recent times, SCs have found tremendous applications in various fields such as consumer electronics, renewable energy, military applications, etc. The automotive industry is one of the major fields in which SCs are extensively being used, mainly in cars, buses and trains where they are primarily used for starting the engine, cold starting at low temperatures and vehicle acceleration. The possibility of using SCs in hybrid as well as electric vehicles is currently being explored. SCs are also being used in applications that we encounter in our day to day lives, such as lifts,



Ramesh Subramaniam
Prof. Ramesh T. Subramaniam is a materials scientist experienced in the preparation, development and characterization of polymers and polymer electrolytes as a source of energy for use in various electrochemical devices. He was selected as a "TWAS Young Affiliate Fellow" in 2009 by The World Academy of Sciences - one of the five from the South \& Southeast Asia and Pacific region. He also received the "UTAR Annual Research Excellence Award" in 2009. In 2010, he received the "Pacifichem Young Scholar Award" from the American Chemical Society and in 2011, the "Young Scientist Award" from IUPAC. In 2012, he received the "IAP Young Scientist Award" and the following year he was selected as a "Young Scientist of the Global Young Academy (GYA)". In 2014 he was selected as one of the "Top Research Scientists Malaysia (TRSM)". It was a great honor for him to be elected as a "Fellow of the Academy of Sciences Malaysia (ASM)" in 2016 and in the same year he received the "International Association of Advanced Materials Scientist Medal" (IAAM Scientist medal) from the International Association of Advanced Materials. In 2017, he was conferred with the "Established Scientist Award" by Royal Society and also elected as a "Fellow of Royal Society of Chemistry (RSC)". He is also a recipient of the "Fulbright Fellowship 2017" with a tenure at the Princeton University, USA, as a Visiting fellow and a recipient of the "International Senior Research Fellowship 2018" at Durham University, UK, where he had a tenure as a Visiting Senior Fellow. He was awarded the "MTSF Science \& Technology Award" by Malaysia Toray Science Foundation (MTSF) in 2018. He has also been honoured with the University of Malaya Excellent Lecturer (Sciences) Award 2019. On the global front, he was the Invited Scientist for World Science Forum and World Economic Forum. cranes, elevators, smart phones, laptops and security systems. ${ }^{8,9}$ An important parameter that researchers are concentrating on is the volumetric energy density of SCs. It is desired that SCs have less volume so that they can be used in consumer electronics. ${ }^{10}$

SCs are chiefly classified into two types namely pseudocapacitors and electrical double layer capacitors (EDLCs). ${ }^{11,12}$ In EDLCs, the absorption and de-absorption of charges take place at the electrode/electrolyte interface within seconds leading to fast charge-discharge rates and excellent cycling stability. The surface area of the electrodes as well as their pore size, distribution and structure has a significant impact on the capacitance of EDLCs. Activated carbon materials, carbon nanofibers and mesoporous carbons are commonly used as electrode materials in EDLCs because of their high surface area and their abundant supply. ${ }^{13-15}$ In contrast, reversible faradaic redox reactions between the electrodes and the electrolyte are responsible for storing energy in pseudo-capacitors. The commonly used electrode materials for pseudo-capacitors include metal oxides such as $\mathrm{MnO}_{2}, \mathrm{NiO}, \mathrm{TiO}_{2}$, polypyrrole, polyaniline and other conducting polymers. ${ }^{16-18}$ Pseudo-capacitors exhibit higher specific capacitance and poor cycling stability as compared to EDLCs.

Current research chiefly focuses on the manufacturing and characterization of flexible electrode materials such as CNTs, ${ }^{19}$ graphene, ${ }^{20}$ etc. and their composites with conducting polymers, ${ }^{21}$ metal oxides, ${ }^{22}$ etc. However, the electrochemical performance of a SC also depends on the material and type of electrolyte and separator used. Solid electrolytes are preferred in flexible SCs as they act as an electrolyte as well as a separator to prevent a short circuit and chemical leakage; furthermore, if an SC is present in the form of a film, it also minimizes the distance of ion transport. ${ }^{23,24}$ Quasi-solid gelled polymer electrolytes demonstrate higher ionic conductivity $\left(10^{-1}-100 \mathrm{mS} \mathrm{cm}^{-1}\right)$ than solid electrolytes $\left(10^{-5}-10^{-3} \mathrm{mS} \mathrm{cm}^{-1}\right) .^{25,26}$

A separator, a vital component that enables free ionic flow and isolates electronic flow, greatly influences the safety and electrochemical performance of SCs. Unfortunately, very few researchers have focussed their attention towards optimising the characteristics of separator membranes i.e. their chemical composition and morphology. ${ }^{27,28}$ Separators have been developed from a variety of sources such as polyolefins, aqua gel and rubber. These separators must (i) be thin and provide electrical insulation so as to avoid a short-circuit between the electrodes, ${ }^{29}$ (ii) be good dielectric materials and exhibit electrochemical stability in the electrolytes used, and (iii) also favour high ionic mobility between the electrolyte and electrode surface. However, separators tend to show low ionic conductivity or dry out and collapse over a period of time. ${ }^{4,30}$ Macro porous separators made from poly(vinylidene fluoride) (PVDF) and poly(vinylidene fluoride-co-hexafluoropropene) (PVDFHFP) show good affinity with the organic liquid electrolyte, which offers high ionic conductivity and more electrolyte retention due to their porous structure. ${ }^{31}$ But the mechanical strength of such macro porous membranes is inferior to that of dense membranes. ${ }^{32}$ The use of microporous separators fabricated from polyolefins is confined due to their sluggish ion 


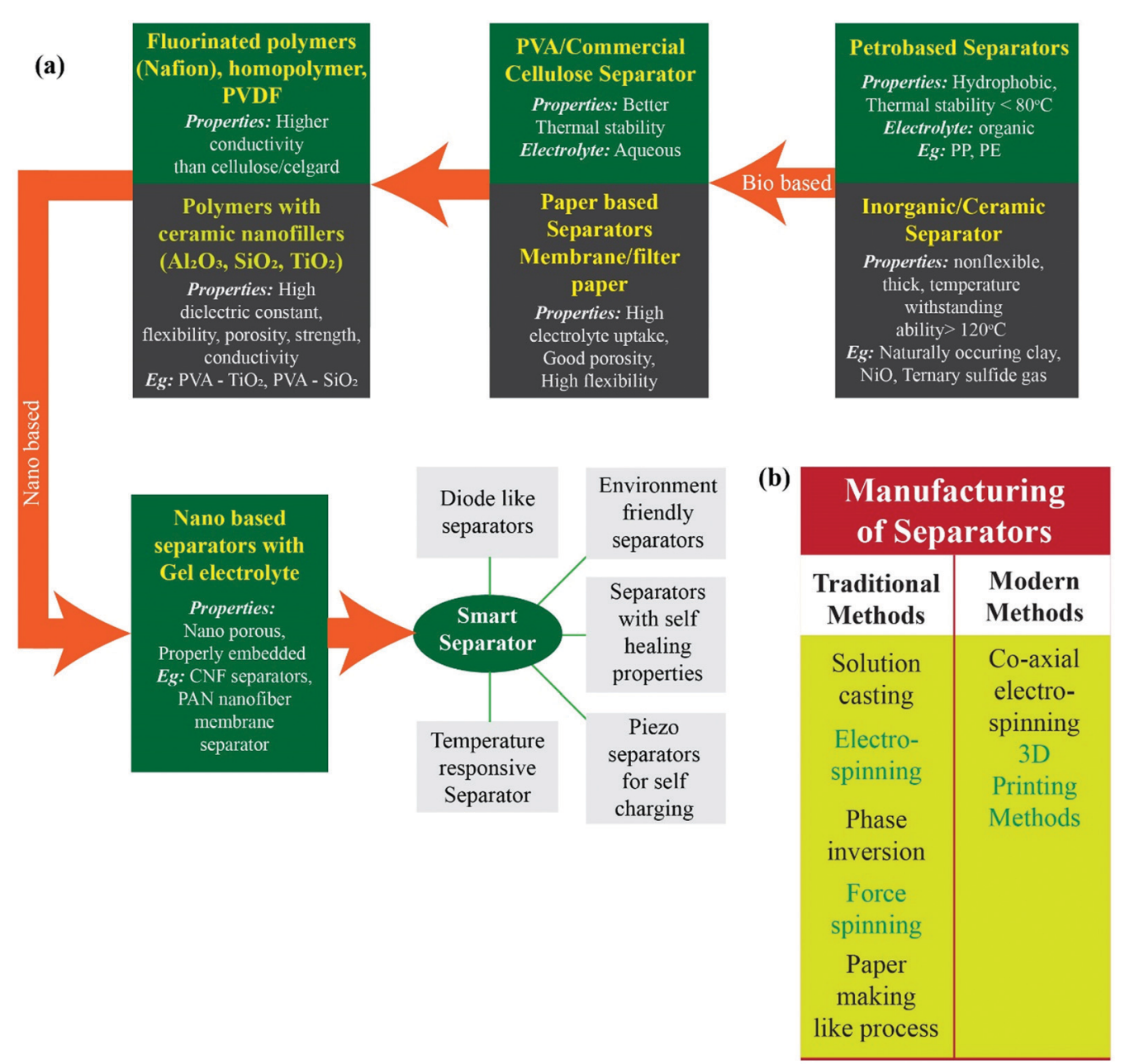

Fig. 1 Progressive evolution in separator (a) materials, and (b) manufacturing processes.

transfer kinetics and poor thermal stability. Currently, the most commonly used dense separator membranes are Nafion and sulfonated poly(ether ether ketone) (SPEEK) membranes. Separators from these membranes are fabricated by immersing them in sulfuric acid solutions. Nafion is mainly composed of a hydrophobic Teflon backbone and hydrophilic sulfonic acid groups. ${ }^{33-35}$ However a major drawback with these membranes is that they are expensive and the raw materials required for their fabrication are limited with high carbon footprint. ${ }^{36,37}$ Fig. 1 illustrates the progress made in the choice of materials used to fabricate separators and the manufacturing processes that are used.

The choice of the separator depends on the application involved. Separators employed in structural members should carry mechanical load. Wearable electronics need flexible separators. For applications like oil drilling, separators should withstand high temperatures with least compromise on their performance. Sometimes they should be able to harvest as well as store energy. This review focuses on the different materials being recently used as separators, various fabrication processes involved and their combined effect on the performance of SCs.

\section{Materials for separator membranes}

\subsection{Polymer based membranes}

Polymer based materials are promising candidates for use as separators as they possess high chemical and mechanical resistance apart from being cheap, abundant and easily processible. Polypropylene (Celgard) separators are the most commonly used commercial separators in SCs. Several other polymers such as polyethylene (PE), PVDF, PVDF-HFP, poly(vinyl chloride) (PVC), poly(ethylene glycol) (PEG) and poly(ethylene oxide) (PEO) have also been used to fabricate separators for SCs. ${ }^{38-40}$ Polymer based separators can be fabricated using a variety of methods. Electrospinning is commonly used to fabricate both single component membranes (e.g. PVDF) and composite separator membranes (PVDF combined with nano sized ceramic particles or blend with other polymers). The porosity and pore size of the separator membranes can be closely controlled using this process. ${ }^{41,42}$ Electro-spun fibre membranes can be applied over electrodes as separators as they are highly porous with large specific surface area and have a wide electrochemical performance window compared to commercial separators. ${ }^{43}$ Compared with separators 
manufactured by solution casting or the phase inversion method, electro-spun membranes offer more electrolyte uptake due to high porosity, reduced interfacial resistance and faster ionic diffusion. ${ }^{44}$ The electrospinning process was used to fabricate two separator membranes namely TUX5 (25\% PVDF solution dissolved in $N, N$-dimethylacetamide (DMA)) and TUX10 $(22.5 \%$ PVDF solution dissolved in $N, N$-dimethylformamide (DMF)-acetone mixture). ${ }^{45}$ The influence of the temperature and separator material characteristics such as porosity and composition on the performance of SCs was studied. A meso-macro porous melted structure was observed in the SEM micrographs of the TUX5 separator (thickness $\sim 10 \mu \mathrm{m}$ ) which was mainly attributed to the high PVDF concentration and rapid polymer solution feed rate. ${ }^{46,47}$ On the other hand, a uniform structure of fibres was observed in the SEM images of TUX10 separator membranes (thickness $\sim 20 \mu \mathrm{m})$. The porosity in TUX10 $(\sim 91 \%)$ was also found to be much higher than that in TUX5 membranes $(\sim 40 \%)$. This resulted in higher frequency series resistance in TUX5 as compared to that in TUX10 separator membranes. The relaxation time constant was influenced by the temperature and separator properties. The specific power of SCs employing TUX10 separators was 5 times lower at $-30{ }^{\circ} \mathrm{C}$ as compared to the maximum specific power which was observed at $24{ }^{\circ} \mathrm{C}$ as it also depends on the temperature and separator material parameters like porosity. Aarthi et al. fabricated separator membranes by varying the concentration of PVDF $(5 \%$ to $25 \%)$ in 50:50 wt\% of DMA and tetrahydrofuran using the electrospinning process. ${ }^{48}$ In a similar way, it was observed that the average diameter of the fibres was enhanced with the increasing concentration of PVDF. However, membranes with $20 \%$ concentration of PVDF were found to be optimum as it exhibited promising properties such as high thermal stability up to $450{ }^{\circ} \mathrm{C}$, maximum electrolyte uptake of $200 \pm 2 \%$, a porosity of $86.8 \pm 2 \%$ and a crystallinity of $42.7 \%$. The high porosity and high electrolyte uptake in separator membranes with $20 \%$ PVDF were attributed to the lower fibre diameter $(400 \pm 8 \mathrm{~nm})$ as compared to the other membranes.

He et al. employed electrospinning followed by the phase separation method to manufacture porous PAN nanofiber separators from polyacrylonitrile/polyvinylidene fluoride (PAN/PVP) blends where PVP, a separated phase, was used as a pore forming agent (Fig. 2a). ${ }^{49,50}$ Increasing concentrations of PVP (up to PAN: PVP-10:5 wt \%) in the blend increased the pore size (and hence an increased specific area and meso/macropore capacity) of the electrospun PAN nanofibers after the removal of PVP (Table 3). Due to this, the electrolyte uptake of such porous nanofibers was much higher as the electrolyte was not only adsorbed on the surface but also impregnated into the meso/macropores of the separator (Fig. 2h). Faster ion diffusion corresponds to lesser electrical double layer forming time.

The phase inversion process is widely used in the fabrication of porous SC membranes as it is cheaper and more efficient as compared to electrospinning. Karabelli et al. used the phase inversion method to fabricate microporous separator membranes from PVDF and PVDF-HFP using acetone as a solvent. ${ }^{32}$ The PVDF separators displayed good mechanical properties and had a high porosity of $80 \%$. The authors also reported that the PVDF separators exhibited a higher value of ionic conductivity $\left(18 \mathrm{mS} \mathrm{cm}{ }^{-1}\right.$ ) as compared to Celgard ${ }^{\mathrm{TM}}$ (commercial polyolefin separators with $4 \mathrm{mS} \mathrm{cm}{ }^{-1}$ ) and cellulose separators $\left(10 \mathrm{mS} \mathrm{cm}{ }^{-1}\right)$ when filled with a molar solution of tetraethylammonium tetrafluoroborate (TEABF4) in acetonitrile. Xie et al. fabricated symmetric SCs using two different carbon materials namely activated carbon (AC) (specific surface area of $1187 \mathrm{~m}^{2} \mathrm{~g}^{-1}$ ) and nitrogen enriched activated carbon (N-AC) (specific surface area of $1744 \mathrm{~m}^{2} \mathrm{~g}^{-1}$ ) as electrodes and a PVDF membrane as a separator. ${ }^{51}$ The PVDF membrane was fabricated through the phase inversion process and modified using poly (vinyl alcohol) (PVA) and glutaraldehyde (GA). The decreased contact angle for the modified PVDF membrane (from 73.5 to $61.0^{\circ}$ ) indicated the reduced surface free energy and increased hydrophilicity (Fig. 2b and c). These modifications did not change the thickness of the membrane significantly $(\sim 20 \mu \mathrm{m})$. The membrane possessed an asymmetrical structure comprising mainly of honeycomb like nano sized pores in the skin layer and finger like large pores in the sub layer, providing a sufficient electrolyte reservoir and channels for ion diffusion. (Fig. $2 \mathrm{~d}-\mathrm{g}$ ) The decrease in porosity of the membranes $(72.4 \%$ to $64.4 \%)$ post modification was attributed to the vacant pores being occupied by cross-linked PVA and GA molecules. SCs fabricated using the unmodified PVDF separators showed less specific capacitance because of being poorly hydrophilic and was unable to store sufficient amount of electrolyte, thus hindering the movement of free electrolyte ions. The specific capacitance of AC/PVDF SCs was reported to fall dramatically from $69 \mathrm{~F} \mathrm{~g}^{-1}$ to $4 \mathrm{~F} \mathrm{~g}^{-1}$ as the current density increased from $0.1 \mathrm{~A} \mathrm{~g}^{-1}$ to $10 \mathrm{~A} \mathrm{~g}^{-1}$ while in the case of AC/modified PVDF SCs, the specific capacitance decreased from $43 \mathrm{~F} \mathrm{~g}^{-1}$ to $22 \mathrm{~F} \mathrm{~g}^{-1}$ as the current density increased from $10 \mathrm{~A} \mathrm{~g}^{-1}$ to $50 \mathrm{~A} \mathrm{~g}^{-1}$ (Fig. 2i). The better retention of capacitance in AC/modified PVDF SCs was due to low internal resistance as compared to AC/PVDF SCs.

Apart from the phase inversion process and electrospinning, other novel methods have also been used to fabricate polymer based separators. Hashim et al. demonstrated a cost-effective method of fabricating SCs. ${ }^{33}$ The authors prepared a separator from a mixture of hybrid polymer electrolyte PVA (70\%) and phosphoric acid $(30 \%)$ which was immersed in a mixture of lauroyl chitosan and poly(methyl methacrylate) (PMMA). PVA and lauroyl chitosan were chosen as they possess good mechanical properties and the latter also has the ability to retain high levels of ionic liquids. ${ }^{52,53}$ The separator was sprinkled with $0.15 \mathrm{~g}$ of commercially prepared multi-walled CNTs on either side following which it was assembled into an innovative SC tester. The authors also observed a very high ionic conductivity of 64.2 and $1.84 \mathrm{mS} \mathrm{cm}{ }^{-1}$ when electrochemical impedance spectroscopy (EIS) was carried out in an interval of 7 days. Coaxial wet spinning is one such process which was used to fabricate PVDF nanofiber separators whose thickness was controlled by regulating the PVDF content (5 wt $\%$ to $30 \mathrm{wt} \%) .{ }^{54}$ $10 \mathrm{wt} \%$ of PVDF was found to be the ideal concentration in 

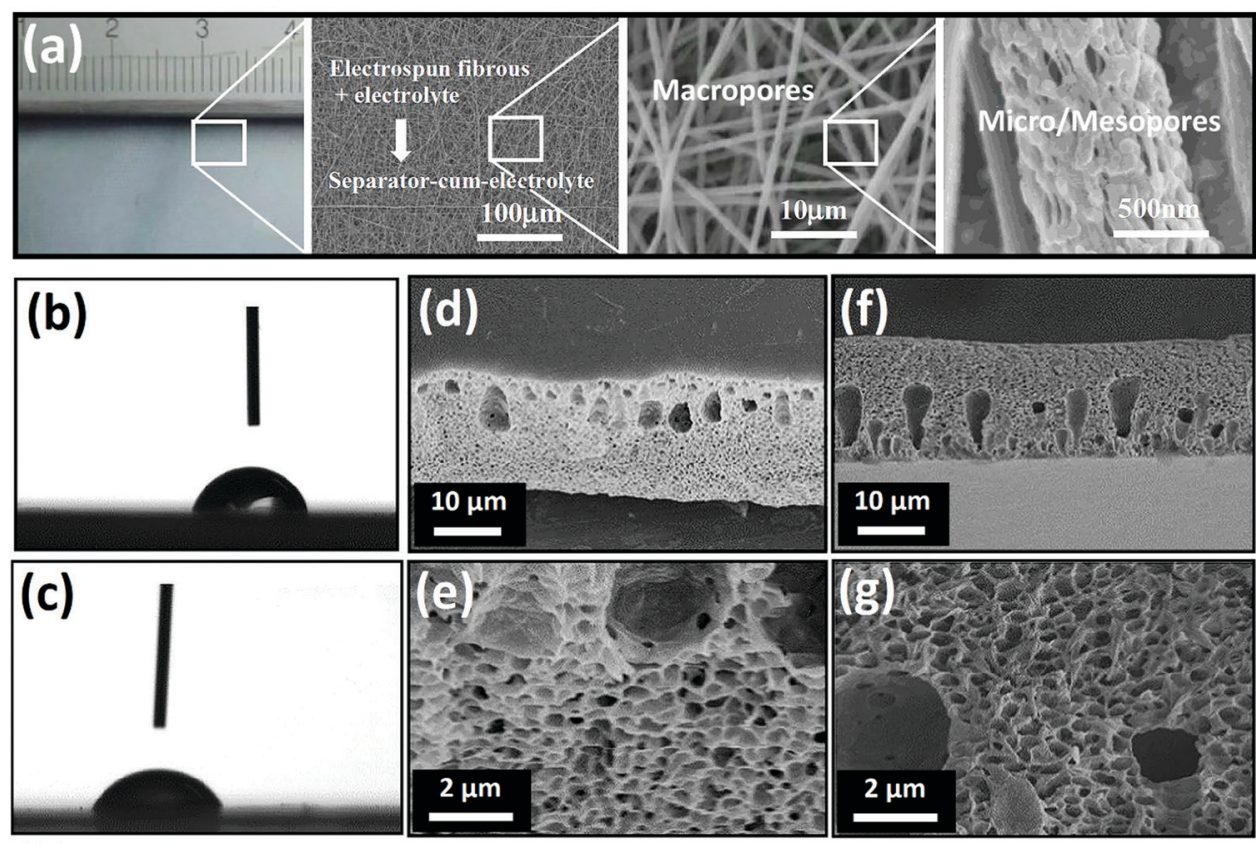

(h)



(i)

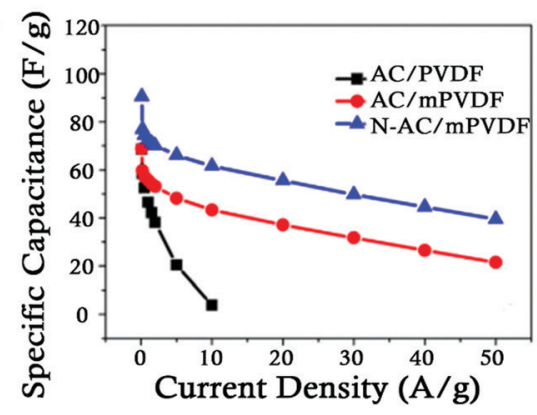

Fig. 2 (a) Hierarchical porous structure of separators fabricated from PVDF fibres. Reproduced with permission. ${ }^{49}$ (b) Contact angle test for PVDF. (c) Contact angle test for modified PVDF. ( $d$ and e) SEM images of PVDF. ( $f$ and g) SEM images of modified PVDF. (h) Plot of the electrolyte uptake vs. time of various separators. Reproduced with permission. ${ }^{50}$ (i) Specific capacitance vs. current density. Reproduced with permission. ${ }^{51}$

the separator. Though the separator displayed a highly wrinkled network architecture, it favoured a large contact between the electrode/electrolyte and rapid diffusion of electrolyte ions with a minimum risk of a short circuit. The separator also exhibited exceptional flexibility as no change was observed on bending the separator at angles up to $180^{\circ}$. Even after 100 such bending cycles $\left(0^{\circ}\right.$ to $\left.180^{\circ}\right)$, only a $3 \%$ drop in the specific capacitance was reported. The SC (graphene/PVDF nanofiber/ graphene) fabricated using this separator has potential to be used in flexible and foldable devices as it can undergo twisting, coiling, knotting, etc. It displayed promising electrochemical properties (Table 3 ).

The use of polymer based membranes in SCs is highly restricted due to their limited electrolyte wettability owing to their inherent hydrophobicity, low ionic conductivity and low porosity. ${ }^{60}$ In order to address this limitation, radio frequency (RF) air plasma treatment was used by Vargun et al. to improve the wettability of a porous polylactic acid (PLA) based biodegradable separator, commercially available Celgard 2400 and NKK-MPF30AC-100 separators. ${ }^{56}$ The water contact angles were decreased in all the three separators post plasma treatment.
The plasma treatment led to the formation of super hydrophilic surfaces (water contact angle $=0^{\circ}$ ) in PLA and NKK-MPF30AC100 separators. The separators also showed improved water uptake values as well as higher ionic conductivities in $1 \mathrm{M}$ $\mathrm{H}_{2} \mathrm{SO}_{4}$ and $1 \mathrm{M} \mathrm{Na}_{2} \mathrm{SO}_{4}$ electrolytes post plasma treatment (Table 3). The higher ionic conductivities were attributed to the improved hydrophilicity of the separator membranes. The improved wettability of Celgard 2400 and the PLA separators were attributed to two major factors namely the formation of an oxidized nano layer and the introduction of functional groups on the separator surface. The mechanical property analysis of the membranes revealed that the RF-PLA membranes exhibited good tensile properties despite their highly porous nature (Table 1). Surface modifications of polyamide and polypropylene non-woven fabrics based separators using low energy plasma also resulted in an improved wettability of the separators which was attributed to the surface oxidation of polymers. ${ }^{61}$ The improved wettability led to a reduction in the total wetting time of the separator as well as influenced an increase in the conductivity of the electrolyte present inside the separator. 
Table 1 Mechanical properties of SC separators

\begin{tabular}{|c|c|c|c|c|}
\hline Separator material & Young's modulus (MPa) & Tensile strength (MPa) & Elongation at break (\%) & Ref. \\
\hline SPAES/PEO-10 wt $\%$ & - & 39.1 & 15.4 & \\
\hline SPAES/PEO-50 wt $\%$ & - & 19.0 & 41.5 & 55 \\
\hline SPAES/PEO-60 wt $\%$ & - & 7.0 & 4.7 & \\
\hline RF-PLA & $327.1 \pm 64.2$ & $15.2 \pm 9$ & $10.9 \pm 2.4$ & \\
\hline RF-Celgard 2400 & $481.6 \pm 56.6$ & $20.5 \pm 2.1$ & $6.7 \pm 1.6$ & 56 \\
\hline RF-NKK-MPF30AC-100 & $62.7 \pm 15.4$ & $3.3 \pm 0.8$ & $44.2 \pm 6.5$ & \\
\hline Porous cellulose (ACR-7) & 5430 & 71.71 & - & 57 \\
\hline Porous cellulose ( $8 \mathrm{wt} \%)$ & 2010 & 29.22 & - & 58 \\
\hline Mesoporous cellulose membrane & 8930 & 171.5 & - & 59 \\
\hline
\end{tabular}

2.1.1. Gel polymer electrolyte separators. The use of liquid electrolytes in SCs is accompanied by its own set of challenges such as preventing leakages, avoiding the use of corrosive liquids, maintaining high safety standards, avoiding bulky shapes of SCs due to the liquid electrolytes, etc. The demand for flexible, thin and lightweight energy storage devices to be used in portable electronic devices is also on the rise. It is essential that all components used in such devices should be able to withstand mechanical deformation and in certain cases they must exhibit visual light transmission. Gel polymer electrolytes which play the dual role of separators and electrolytes have shown promise to meet these requirements as they are flexible, possess high ionic conductivity $\left(10^{-1} \text { to } 100 \mathrm{mS} \mathrm{cm}^{-1}\right)^{62}$ and can be shaped into thin films. PVA has shown great potential as a matrix material for gel polymer electrolytes and has been extensively used as an electrolyte and a separator in flexible transparent SCs (FTSCs). ${ }^{21,63-65}$ The performance of the gel polymer electrolyte is further enhanced by the addition of redox additives. The use of the redox additives is to facilitate redox reactions at the electrode-electrolyte interface which affects the capacitance of the SC. Such PVA based gel polymer electrolytes were fabricated by Feng et al. using 1-anthraquinone sulfonic acid sodium (AQSS) ${ }^{62}$ and bromamine acid sodium (BAAS) ${ }^{66}$ as redox additives and were used as separators as well as electrolytes. SCs having gel polymer films with redox additives displayed a higher energy density and specific capacitance compared with the films without it (Table 3). The ideal amount of the redox additive was $0.1 \mathrm{~g}$ as the maximum value of specific capacitance was achieved at this value. Higher concentrations of the redox additives led to their crystallization in the gel polymer which hindered the transportation of free ions. The gel polymer films also exhibited good stretchability as the PVA- $\mathrm{H}_{2} \mathrm{SO}_{4}-\mathrm{BAAS}$ as well as PVA- $\mathrm{H}_{2} \mathrm{SO}_{4}-\mathrm{AQSS}$ films was able to stretch as well as compress above $300 \%$. Stable capacitive performance at various stretching rates (0 to $100 \%$ ) was observed for both the films. A flexible gel polymer PVA-KOH$\mathrm{K}_{3}\left[\mathrm{Fe}(\mathrm{CN})_{6}\right]$ exhibiting excellent mechanical properties and capable of being used as an electrolyte separator was fabricated by Ma et al. ${ }^{67}$ This gel polymer could be stretched to $250 \%$ and bent into a shape of a circular arc to $180^{\circ}$ without fracturing. Apart from excellent mechanical properties, the SC also exhibited excellent electrochemical properties (Table 3 ).

The electrolyte separator gel polymer films used in FTSCs are prone to getting compressed when the SCs are subjected to compression and bending. The change in the thickness of these films results in a change in the electrode spacing leading to unstable capacitance performance. In order to control the electrode spacing, spacers in the form of monodispersed polystyrene (PS) microspheres were mixed with PVA-LiCl gel which performed the role of an electrolyte separator. ${ }^{68}$ The diameter of the PS microspheres (20, 40 and $80 \mu \mathrm{m})$ determined the spacing between the indium tin oxide-polyethylene terephthalate (ITO-PET) glass electrodes. The rectangular like shape of the CV curves of the ITO-PET/PVA-LiCl-PS/ITO-PET SC at a scan rate of $100 \mathrm{mV} \mathrm{s}^{-1}$ suggested an ideal behaviour of the SC (Fig. 3a). The SCs with 20, 40 and $80 \mu \mathrm{m}$ PS microspheres exhibited a specific capacitance of $27.3,28.2$ and $23.5 \mu \mathrm{F} \mathrm{cm}^{-2}$, respectively. A comparison of the properties of FTSCs with and without PS microspheres showed that both FTSCs exhibited similar current densities and capacitance performance under normal operating conditions However, under bending conditions, the FTSC with PS microspheres showed a nearly unchanged CV curve when bent from 0 to $180^{\circ}$ while the FTSC without PS microspheres exhibited CV curves which changed from rectangular to a shuttle like shape as displayed in Fig. $3 \mathrm{~b}$ and c. The change in the shape of the CV curve was attributed to extra sheet resistance and internal resistance caused due to uneven electrode spacing. ${ }^{69}$ The SC demonstrated the best performance with a specific capacitance of $147.1 \mu \mathrm{F} \mathrm{cm}^{-2}$ when electrode spacing was controlled using $40 \mu \mathrm{m}$ microspheres.

The challenge with the flexible SCs developed for wearable electronics is to offer consistent electrochemical performance during stretching, twisting and bending. Li et al. developed vertically aligned $\mathrm{PVA}-\mathrm{H}_{2} \mathrm{SO}_{4}$ (APH) hydrogel films (employed as an electrolyte separator); manufactured by freeze-thawing and directional-freezing methods as shown in Fig. $4 \mathrm{a}^{70}$ In situ growth of poly(aniline) (PANI) electrodes on both sides of this film was achieved to form an integrated SC (APH-PANI). It exhibited 4.65 times higher specific capacitance $\left(25.85 \mathrm{mF} \mathrm{cm}^{-2}\right.$ at $0.05 \mathrm{~mA} \mathrm{~cm}{ }^{-2}$ ) compared to the $\mathrm{SC}$ with a random network (PH-PANI). This SC demonstrated a consistent and stable electrochemical performance during various deformations (Fig. 4b and c). The APH-PANI film also displayed self-healing ability by reorganizing its dynamic physical hydrogen bonds (Fig. 4a and d-f). ${ }^{71,72}$ In a similar way, Hsu et al. developed hydrogels (separator/electrolyte) based on inexpensive natural polymers of gelatin and cellulose nano-crystals (CNCs). ${ }^{72}$ Mussel inspired tannic acid (TA) was used to treat this hydrogel and endow it 




(b)

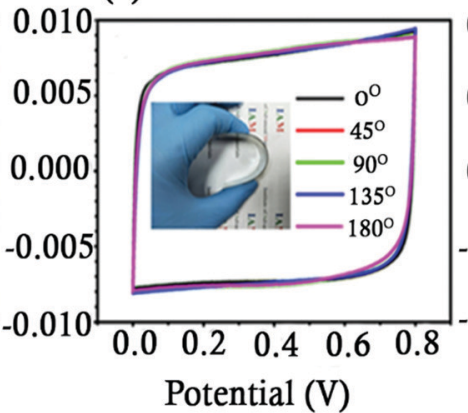

(c)

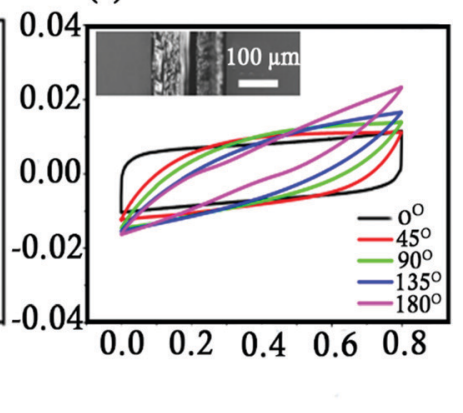

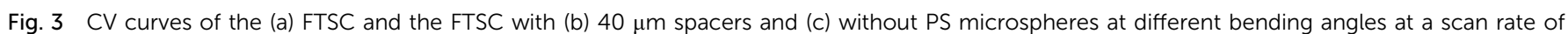
$100 \mathrm{mV} \mathrm{s}^{-1}$. Reproduced with permission. ${ }^{68}$

with self-healable properties. ${ }^{73}$ This separator exhibited autonomous self-healing within $6 \mathrm{~h}$ at room temperature and did not require any external stimuli for the same. A flexible, nontoxic, biodegradable, and biocompatible SC was manufactured by coating PANI and RGO on either sides of this hydrogel. It displayed 84, 69 and $82 \%$ retention of specific capacitance, energy density, and power density respectively compared to its original values after five cuts and healing cycles. Such selfhealable SCs have potential uses in wearable energy storage devices, sensors, e-skins, etc.

To impart mechanical strength and low temperature tolerance to flexible energy storage devices, Yu et al. developed an all-in-one SC with a novel, hydrogen-bonding reinforced, dualcrosslinked hydrogel (separator/electrolyte) made of poly(vinyl alcohol), acrylic acid, and $\mathrm{H}_{2} \mathrm{SO}_{4}$ (PVA-AA-S) as shown in Fig. $4 \mathrm{~g}$ and $\mathrm{h}^{74}$ This hydrogel did not only tolerate high compressive stress (0.53 MPa) and demonstrated high stretchability (up to $500 \%$ ) but also displayed high ionic conductivity ( $75 \mathrm{mS} \mathrm{cm}^{-1}$ ) (Fig. 3i). Strong and abundant hydrogen bonding formed between PVA, PAA chains and water molecules was responsible for this superior performance. ${ }^{75}$ The SC so formed was resilient to various thermo-mechanical stimuli and also exhibited very high capacitance retention for repeated processes as shown in Fig. 4j. This SC was also able to retain $80 \%$ of capacitance even after working at $-35{ }^{\circ} \mathrm{C}$ for 23 days and hence made themselves capable of serving at high altitudes, thanks to the excellent low temperature resistance of this hydrogel. Hydrogen bonding also stimulates the self-healing properties, permitting the self-assembly of all-in-one SCs. ${ }^{76}$ It was surprisingly found that the hydrogel when cut into two halves self-healed and reformed within one hour, displaying the excellent self-healing properties of this hydrogel. Li et al. obtained a cellulose based, flexible hydrogel employing polydopamine (PDA) as a crosslinking agent between polyacrylamide (PMA) and cellulose. ${ }^{77}$ At a ratio of 0.4 (DA/PM), the double cross-linking ( $\Pi-\Pi$ stacking in PDA and hydrogen bonds formed in the gel network) ensured superior mechanical (high flexibility) and self-healing properties. After $\mathrm{Fe}^{3+}$ functionalization, this hydrogel was converted to an aerogel separator. The EDLC using a KOH saturated aerogel membrane displayed $127 \%$ higher capacitance $\left(172 \mathrm{~F} \mathrm{~g}^{-1}\right)$ than the commercial polypropylene (PP) separator membrane $\left(75.8 \mathrm{~F} \mathrm{~g}^{-1}\right)$ at $1 \mathrm{~A} \mathrm{~g}^{-1}$. It also displayed high capacitance retention $(84.7 \%)$ with longer life (10 000 cycles), especially due to the high electrolyte retention (549\%). The integrated micro-SC fabricated employing this hydrogel displayed remarkable areal and volumetric capacitances of $275.8 \mathrm{mF} \mathrm{cm}^{-2}$ and $394.1 \mathrm{~F} \mathrm{~cm}^{-3}$ at $10 \mathrm{mV} \mathrm{s}^{-1}$ respectively.

2.1.2. Polymers with carbon nano-tubes. Recently, attempts were made to modify the electrically insulating/unbiased membranes in the active (diode like) layers. ${ }^{78,79}$ The effect of depositing electronically structured p-type and n-type single walled CNTs on either sides of the separator membranes was studied by Chowdhuri et al. ${ }^{80}$ (Fig. 5a and b) On pressing the layers together, a diode like behaviour was observed. The separators exhibited both capacitance and resistance to ion flow and were permeable to the ionic current. The authors noted that a single p-type layer (CNTs coated with polyvinylpyrrolidone) exhibited an additional capacitance of $15 \mathrm{~F} \mathrm{~g}^{-1}$ while a single n-type layer (CNTs coated with polyethylene imine) exhibited an additional capacitance of $7.5 \mathrm{~F} \mathrm{~g}^{-1}$. Since the layers were connected in parallel, the net additional capacitance was $22.5 \mathrm{~F} \mathrm{~g}^{-1}$. Apart from these, a further increase in the capacitance was observed because of the junction formed due to the p-type and n-type ions. These effects resulted in an overall increase of $15 \%$ in the capacitance of the SC when porous carbon electrodes were used $\left(400 \mathrm{~F} \mathrm{~g}^{-1}\right) \cdot{ }^{80,81}$ They also demonstrated that these ionic-liquid filler SCs displayed a decrease in the equivalent series resistance compared with the cells having commonly used separators. ${ }^{82}$

\subsection{Polymer-ceramic based membranes}

Dielectric materials comprising polymers and ceramics are commonly used as separators to achieve high power and energy densities. Polymers exhibit excellent mechanical and chemical stability but have a low dielectric constant. On the other hand, ceramics have a high dielectric constant, high ionic conductivity and high thermal stability but lack mechanical strength. ${ }^{85,86}$ Alvarez et al. combined the desired properties of both ceramics and polymers by fabricating polymer/ceramic composite (PCC) separators comprising of PVDF, polypropylene (PPy) and a mixture of earth based metal titanates such as $\mathrm{SrTiO}_{3}, \mathrm{CaTiO}_{3}$, and $\mathrm{BaTiO}_{3}$ using the phase inversion process. ${ }^{87}$ The porosity of the separator was improved by the addition of lithium chloride. 
(a)

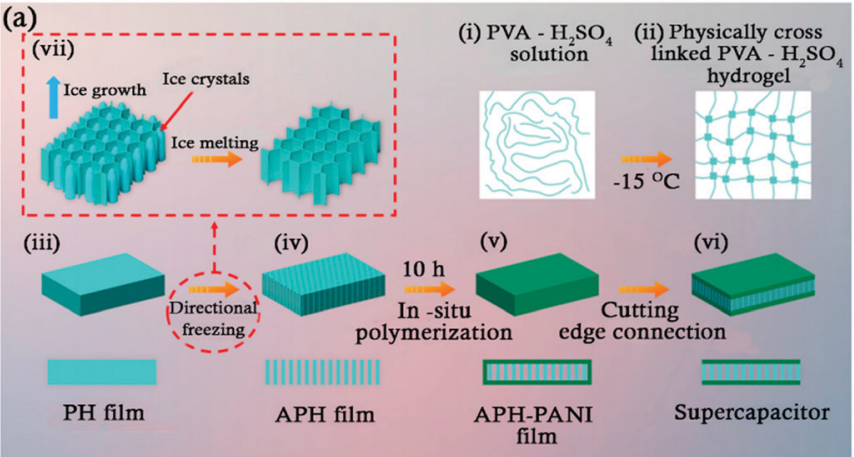

(c) 120

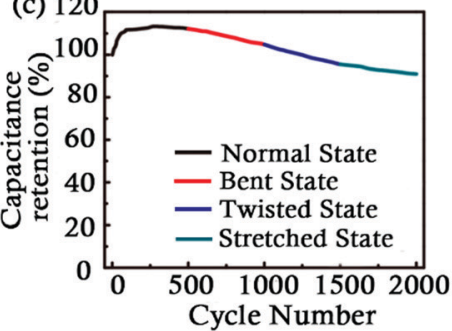

(f)

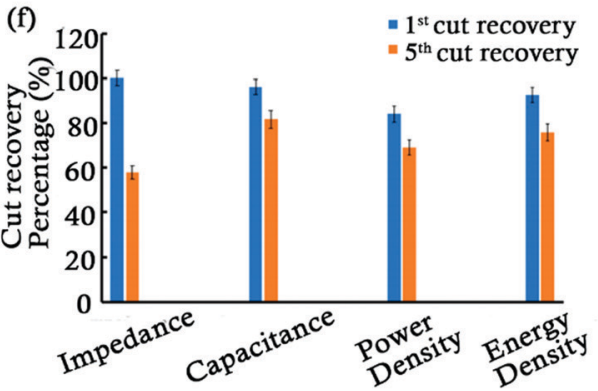

(d)

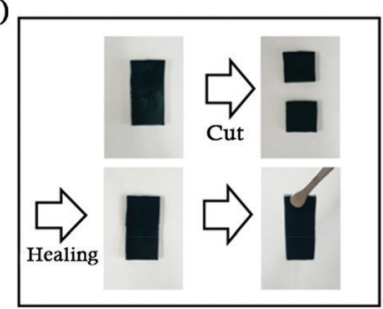

(b)

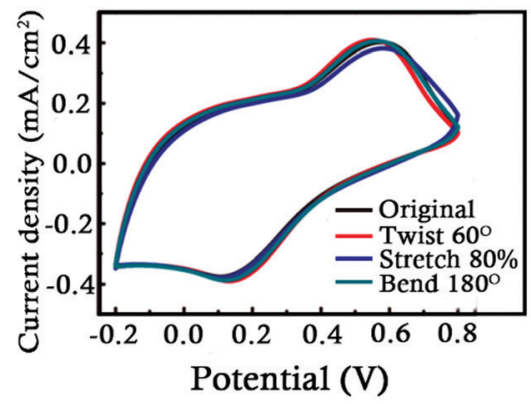

(e)

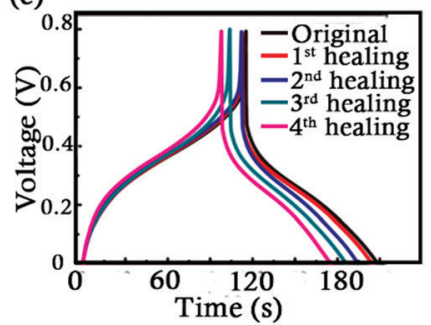

(h)
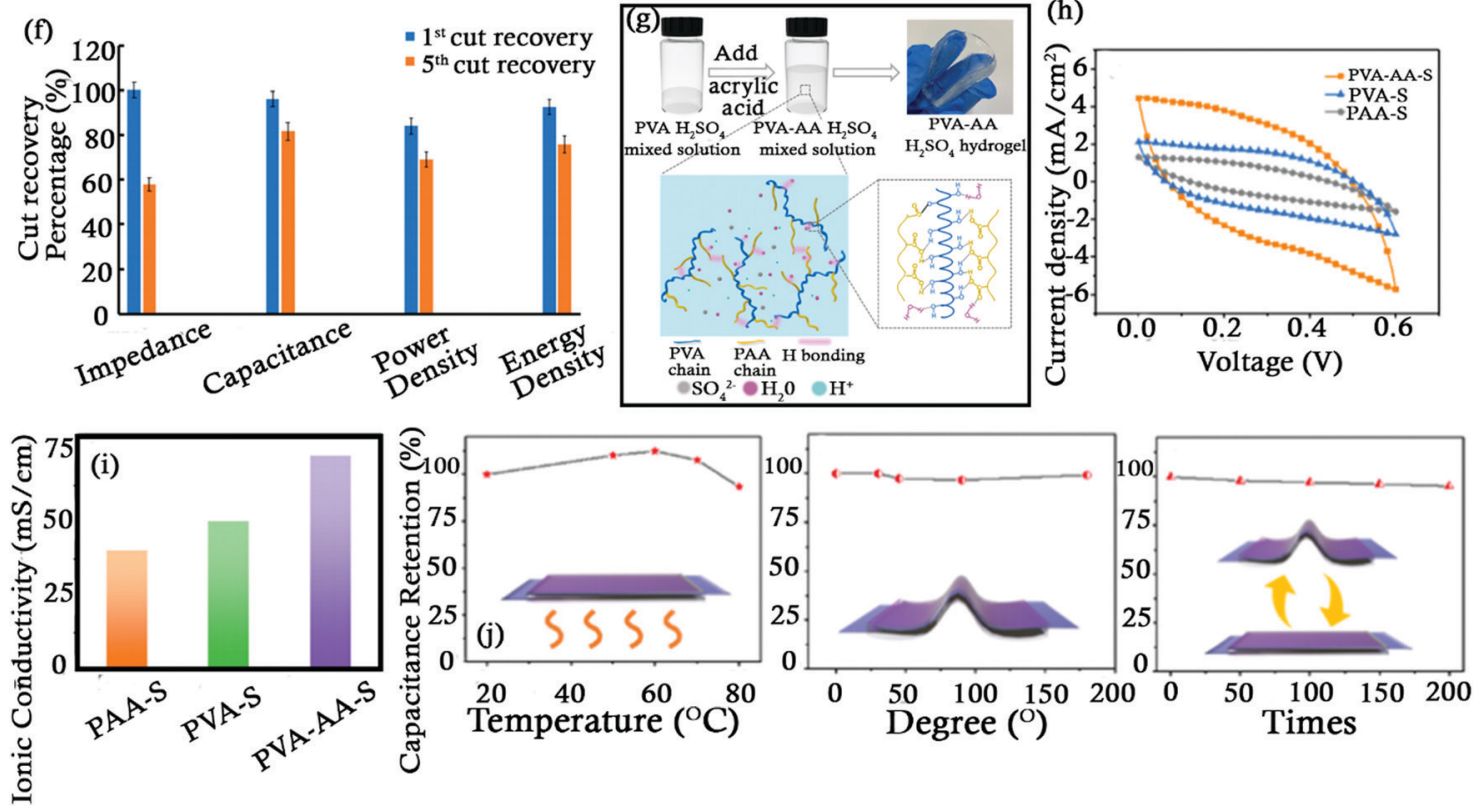

Fig. 4 (a) Schematic diagram showing the fabrication of an APH-PANI SC. (b) CV curves of the APH-PANI SC showing its capacitance retention ability under different conditions. (c) Capacitance retention vs. number of cycles. (d) The process of self-healing in the APH-PANI SC. (e) Voltage vs. time curves with different self-healing times. Reproduced with permission. ${ }^{70}$ (f) Recovery percentage vs. electrochemical performance of a self-healing SC. Reproduced with permission. ${ }^{72}$ (g) Schematic showing the preparation of the PVA-AA-S hydrogel. (h) CV curves of 3 different hydrogels. (i) lonic conductivity of 3 different hydrogels. (j) Capacitance retention of the SC under heating, bending and bending - releasing cycles. Reproduced with permission. $^{74}$

The PCC separators also offered a lower ohmic resistance $(\sim 45 \Omega)$ and had an improved dielectric constant (4.52) as compared to commercially available separators (CelgardEz 2090 grade- ohmic resistance $47 \Omega$, dielectric constant 2.2). The PCC separators were heat treated to allow thermodynamic arrangements of the various components of the separator. The Young's modulus of the PCC separator improved by $71.1 \%$ on average post heat treatment. The improvement in the dielectric constant of PCC separators as compared to that of commercial separators was attributed to the addition of the ceramic into the separator. The specific capacitance of the separator was found to reduce at elevated temperatures. This was attributed to an increase in the density as the pores tend to close at higher temperatures enabling the presence of a higher mass in the same volume.

The control of pore's size and its distribution in the separator membrane is very important as it has an influence on the internal resistance and ionic conductivity of SCs. Ceramic particles can be used to increase the porosity of separators 
(a)



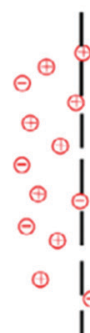

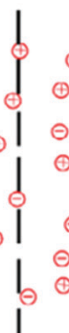

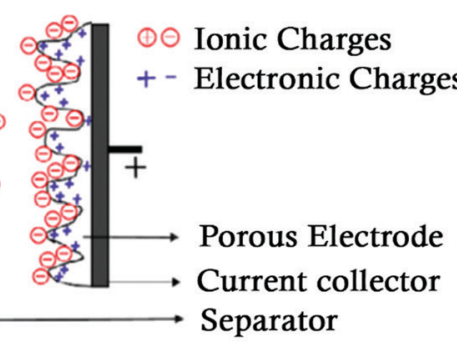

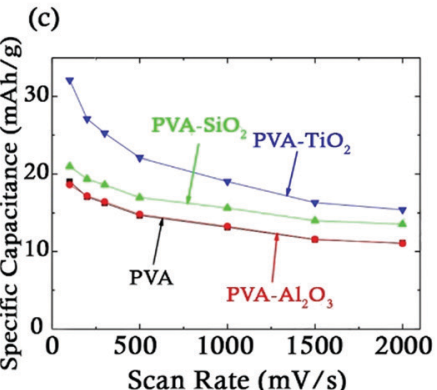

(d)

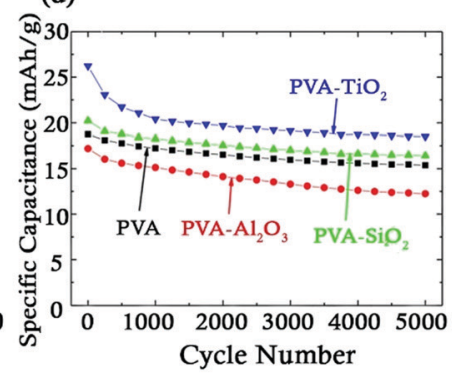

(b)

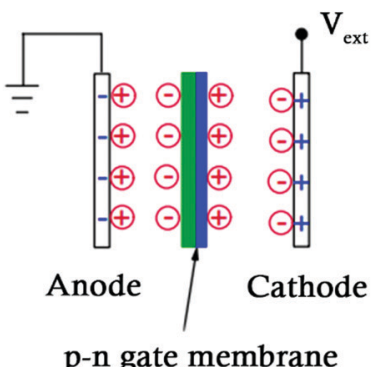

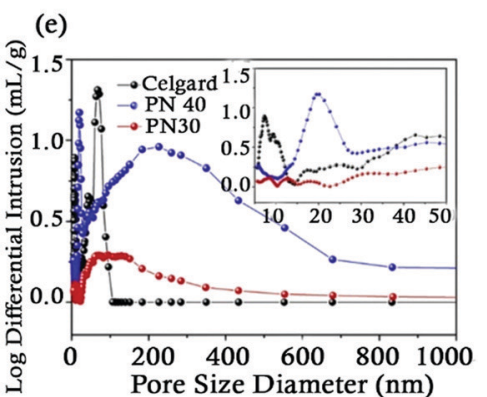

Fig. 5 (a) Schematic of a SC. (b) Mid cell gate structure similar to a diode. Reproduced with permission. ${ }^{80}$ (c) Variation of specific capacitance as a function of scan rates at a potential window of $0-1.5 \mathrm{~V}$, (d) Cycle life of various separators. Reproduced with permission. ${ }^{83}$ (e) Plot of porosity distribution. Reproduced with permission. ${ }^{84}$

having a polymer matrix. PVA-ceramic composite separators were fabricated by adding ceramic particles of $\mathrm{Al}_{2} \mathrm{O}_{3}, \mathrm{SiO}_{2}$ and $\mathrm{TiO}_{2}$ to an aqueous solution of PVA. ${ }^{83}$ This addition of ceramic particles creates amorphous regions in the crystalline polymer matrix, thus creating a more porous morphology leading to an increase in the ionic conductivity (maximum by $100 \%$ in the PVA-TiO ${ }_{2}$ separator). The increase in porosity did not appreciably affect the structural integrity of the separator making them safe for use in flexible energy storage devices. A 68.6\% increase in the specific capacitance of $\mathrm{PVA}-\mathrm{TiO}_{2}$ composite separators $\left(32 \mathrm{~F} \mathrm{~g}^{-1}\right.$ ) was observed when compared with bare PVA separators $\left(19 \mathrm{~F} \mathrm{~g}^{-1}\right)$ at a scan rate of $100 \mathrm{mV} \mathrm{s}^{-1}$ (Fig. $5 \mathrm{c}$ ). But the $\%$ capacitance retention for $\mathrm{PVA}^{-\mathrm{TiO}_{2}}$ was nearly the same as that of the bare PVA separator $(\sim 70 \%)$ after 5000 cycles as shown in (Fig. 5d). It is desired that SCs possess a low internal resistance during the charge/discharge process in order to minimise the energy loss in the form of heat. When a $\mathrm{BaTiO}_{3} /($ PEDOT:PSS) composite was used as a separator in a graphene SC with PVA as the electrolyte, a low internal resistance of $42 \Omega$ was reported. ${ }^{88}$ The lower internal resistance was attributed to the pore size of the separator membrane which was smaller as compared to that of the PVA film. ${ }^{89}$ The graphene SC exhibited a high specific capacitance of $195 \mathrm{~F} \mathrm{~g}^{-1}$.

The pore size in separators can be controlled using different manufacturing processes. However, a majority of the manufacturing processes that control the pores like electrospinning and solvent exchange are expensive and time consuming. Liu et al. employed a low-cost casting (stir-pour-dry) technique to develop a highly porous network of $\mathrm{Al}_{2} \mathrm{O}_{3}$ nanowires (NW)/ polyvinyl butyral (PVB) composite membrane. ${ }^{84}$ At $\mathrm{Al}_{2} \mathrm{O}_{3} \mathrm{NW}$ concentrations between 30 and $40 \mathrm{wt} \%$ (denoted as) PN30 and PN40 in Fig. 5e, this amazing non-woven membrane exhibited high porosity (42-75\%), high flexibility, high strength (>30 MPa), high temperature withstanding ability (up to $200{ }^{\circ} \mathrm{C}$ ), high electrolyte uptake ( $>200 \mathrm{wt} \%$ ), little to no swelling behaviour even at $200{ }^{\circ} \mathrm{C}$, and higher ionic conductivity of up to $13.5 \mathrm{mS} \mathrm{cm}{ }^{-1}$; a performance way better than those of the commercial Celgard separators. Mercury porosimetry measurements revealed higher porosity (42 and 75\%) and broad pore size distributions (5 to $1000 \mathrm{~nm}$ ) for PN30 and PN40 compared to their commercial counterpart (pore size $<20 \%$ for its distribution) (Fig. 5e).

\subsection{Ceramic membranes}

The use of separators fabricated from cellulose, polymers, etc. in SCs employed in high temperature applications such as oil drilling, under hood automotive components, etc. is not feasible as they undergo unreliable shrinkage and deformation at elevated temperatures. For such high temperature applicationspecific SCs, a combination of solid organic electrolytes/ionic liquids $^{90,91}$ as electrolytes along with natural clay/ternary sulphide glass/combinations of ceramic materials is used. ${ }^{92,93}$ SCs were fabricated for such high temperature applications having ceramic based separators, carbon electrodes and a $2 \mathrm{M} \mathrm{KOH}-$ glycerine solution (boiling point of $290.9^{\circ} \mathrm{C}$ ) as an electrolyte. ${ }^{94}$ The ceramic separators mainly comprised of nickel oxide (NiO) and zirconium dioxide $\left(\mathrm{ZrO}_{2}\right)$. NiO was added to the separator membrane as it has a negative temperature coefficient of resistance and thus offers lower resistance at elevated temperatures. This actually enhanced the capacitance at higher temperatures (Table 3). Graphite powder was added as a pore forming agent with its content being varied from 10 to $30 \%$. The addition of graphite also led to an increase in the operating temperature and the pore size in the separator resulting in rapid ion diffusion and enhanced capacitance. The specific 

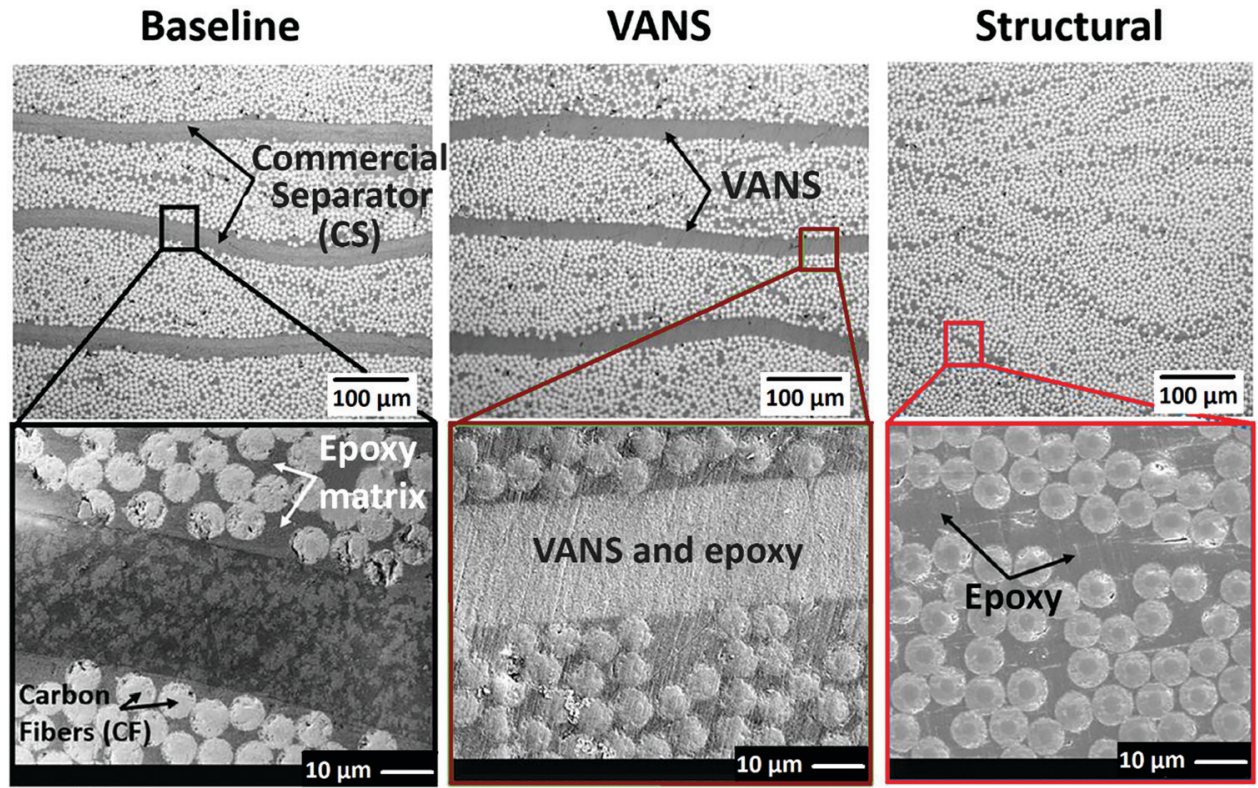

Fig. 6 Morphological comparison of commercial separator, VANS, and traditional monofunctional structural composite interfaces via optical (top) and SEM (bottom) images of interior (4 plies) of the composites. Reproduced with permission. ${ }^{99}$

capacitance increased with an increase in the graphite concentration. However, at graphite concentrations of $40 \%$, the separator membrane exhibited poor mechanical behaviour. SCs with separator membranes having $30 \%$ graphite composition exhibited good electrochemical properties at a temperature of $140{ }^{\circ} \mathrm{C}$ (Table 3).

Apart from high temperature applications, ceramic based separators have also been employed in SCs used for wearable electronic devices. SCs to be used in such devices are characterized by their compactness, flexibility and high energy storage ability. Scalable printing technology has been used to fabricate planar asymmetric SCs for such applications. ${ }^{95}$ Monolithic films were layered one over the other and integrated on a single substrate. The stacked layers were made of $\mathrm{MnO}_{2} /$ poly 3,4ehtylene dioxythiophene: polystyrene sulfonate $\left(\mathrm{MnO}_{2} / \mathrm{PED}\right.$ OT:PSS) as the positive electrode, ionically conducting boron nitride as a separator $(\sim 2.2 \mu \mathrm{m})$, and the graphene nano-sheet as a negative electrode; all were integrated on a single substrate without additives, binders or metal based current collectors. This flexible SC delivered a volumetric energy density of 8.6 $\mathrm{mW} \mathrm{h} \mathrm{cm}^{-3}$ (much higher than any conventional asymmetric SC with two substrates reported); demonstrated $\sim 99 \%$ of the initial capacitance even after bending it by $180^{\circ}$ and a capacitance retention of $92 \%$ after 5000 cycles.

Structural energy storage applications demand that the SC behaves as a structural member and has the ability to carry loads. The separators used in such SCs must contribute to the load carrying capacity without inducing structural defects. This has led to a demand for mechanically robust separators. ${ }^{96,97}$ To reduce the weight of the system, ${ }^{98}$ Acauan et al. proposed the concept of development of multifunctional energy storage devices that can carry load like composites. They fabricated structural separators by covering vertically aligned carbon nano tubes (VACNTs) with $\mathrm{Al}_{2} \mathrm{O}_{3}$ using the atomic layer deposition technique and sintering followed by the removal of CNTs (Fig. 6). ${ }^{99}$ The main function of the CNTs was to control the porosity and align the alumina nanotubes (ANTs). These ANT arrays along with ionic polymer electrolytes formed vertically aligned nano fibre separators (VANS). These VANS were placed between the stackings of uni-directional carbon fibres (electrodes of the SC) to fabricate the multifunctional composite laminate/SC. The presence of ANTs in the polymer electrolyte reduces its crystallinity, thus resulting in high ionic conductivity of VANS. The major advantage of VANS over other separators is its resistance to delamination (de-bonding of adjacent plies due to the weak interface) which is a very common mode of failure in laminated composites. The authors found the strength of the VANS to be similar to that of the structural separator and improved by $47 \%$ as compared to that of a commercial separator. The authors reported that the VANS based laminate exhibited nearly similar mechanical performance to that of the structural separator, whereas it displayed a $47 \%$ increase in tensile strength, $131 \%$ increase in effective stiffness, $51 \%$ increase in inter laminar shear strength compared to commercial separators. However, a $6 \%$ decrease was reported in the inter-laminar shear strength of VANS as compared to that of the structural separator. This decrease was attributed to the presence of interlaminar voids present in VANS.

\subsection{Bio based separator membranes}

2.4.1. Tree leaves as separators. Tree leaves are abundant, easily available, inexpensive and bio-degradable which has led researchers to try and determine whether they can be used as separators for SCs. In one such work, Yao et al. selected biodegradable biomass of Bradyrhizhobium japonicum (BJ) for an electrode material as it possessed a $3 \mathrm{D}$ structure and is enriched with $\mathrm{N}$ content, carbonized it with $\mathrm{ZnCl}_{2}$ activation 
$\left(\mathrm{ZnCl}_{2} / \mathrm{BJ}\right.$ mass ratio $\left.=1.5\right)(\mathrm{BJPC}-1.5)$ to manufacture it in a single step (Fig. 7a). ${ }^{100}$ A soya-bean leaf (SL) that contains more hydroxyl groups on its surface and a hierarchically ordered macroporous network was preferred as a separator. ${ }^{101,102}$ The electrochemical performance of such a SC containing this biomass based electrode (BJPC-1.5) and an SL separator was found to be better than the commercialized cellulose and PP separators (Table 3). Galvanostatic charge/discharge (GCD) curves demonstrated that the initial ohmic drop of the SC employing the SL separator $(0.13 \mathrm{~V})$ was less than that of the cellulose $(0.19 \mathrm{~V})$ and PP separators $(0.28 \mathrm{~V})$ due to its high wettability (52, 41 and 4\%, respectively) as shown in Fig. $7 \mathrm{~b}$ and c.

However, the low porosity of tree leaves serves as a major limitation for its use as separators. Chemical modification (a)

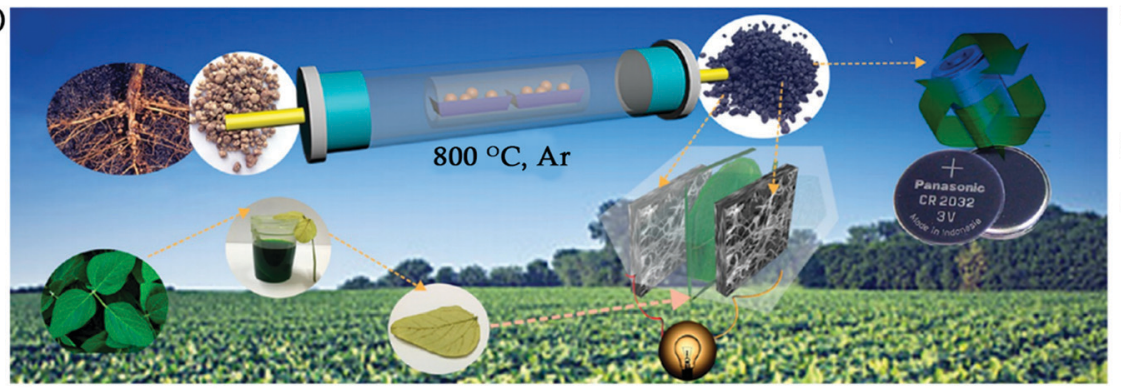

(c)



(f)

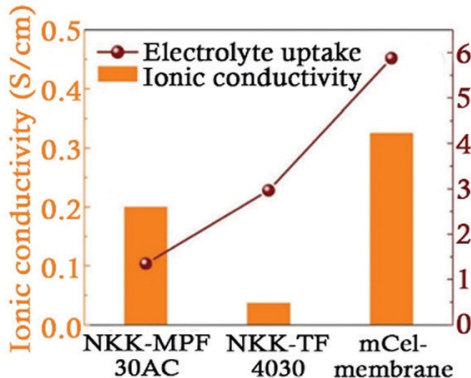

(i)

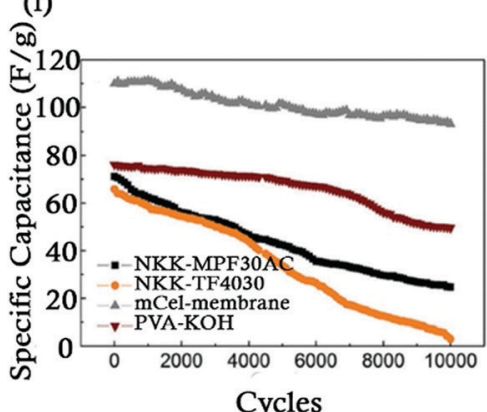

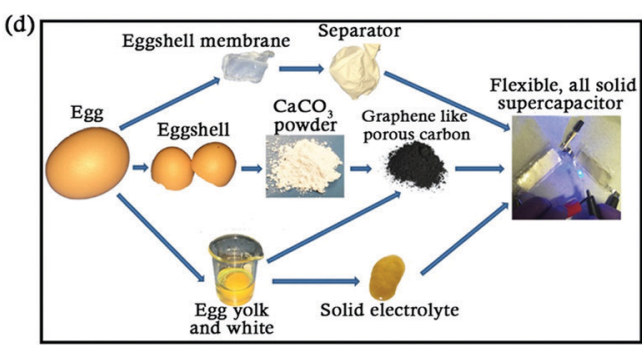

(g)

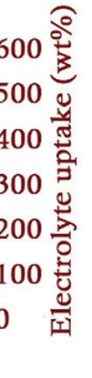

(j)

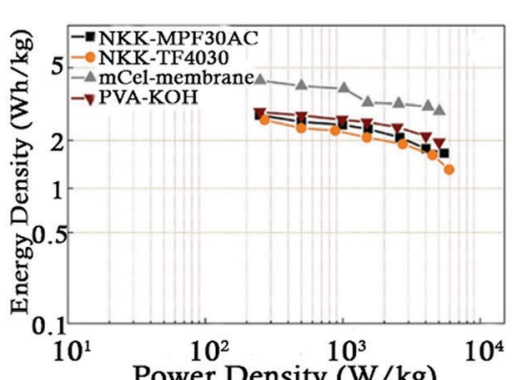

Power Density $(\mathrm{W} / \mathrm{kg})$

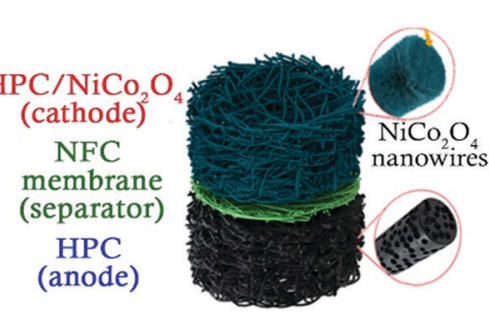

All nanofiber ASC

(k)

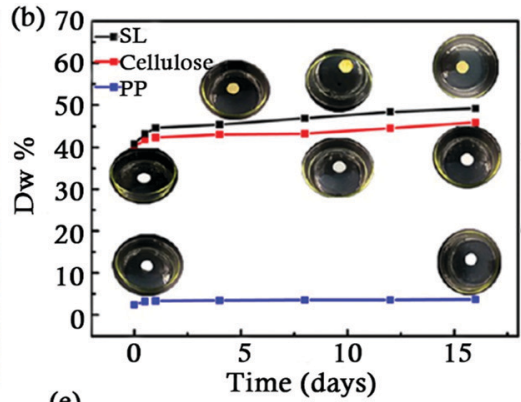

(e)

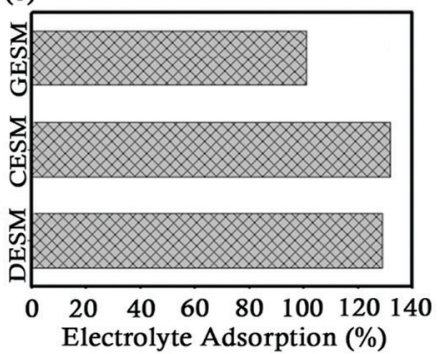

(h)
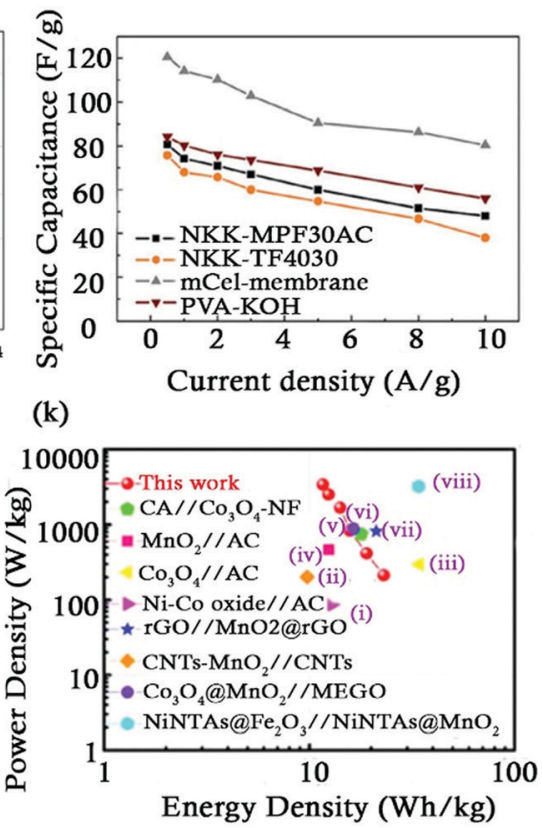

Fig. 7 (a) Preparation of BJPCs, (b) the electrolyte uptake of the separators, (c) GCD curves obtained on using BJPC - 1.5 as the electrode and the three different materials as separators. Reproduced with permission. ${ }^{100}$ (d) An illustration of the various components of eggs used for the fabrication of all solid SCs. Reproduced with permission. ${ }^{110}$ (e) The electrolyte absorption capacity of different membranes. Reproduced with permission. ${ }^{107}$ (f) The electrolyte uptake of the three separators. (g) The ionic conductivity of the three separators. (h) Specific capacitance of the separators at different current densities. (i) Specific capacitance vs. number of cycles. Reproduced with permission. ${ }^{59}$ (j) Schematic diagram of an ASC fabricated using nanofibers. (k) Comparison of electrochemical performance of ASCs with other SCs fabricated in previous studies namely (i) ref. 122, (ii) ref. 123, (iii) ref. 124,(iv) ref. 125, (v) ref. 126, (vi) ref. 127, (vii) ref. 128, and (viii) ref. 129. Reproduced with permission. ${ }^{119}$ 
using alkaline solutions is one of the methods by which the porosity of tree leaves can be improved. This method was used by Jin et al. in their experiments where they carried out the $\mathrm{NaOH}$ activation process on the surface of four different kinds of tree leaves namely cinnamomum camphora (CC), magnolia grandiflora (MG), platanus orientalis (PO) and osmanthus fragrans (OF). ${ }^{103}$ These leaves had different chemical compositions and hence different pore morphologies were observed. A 3-D porous network structure comprising nano-sized and macropores was observed in CC leaves while irregular porous network structures were observed in MG and PO leaves. Lignin and hemicellulose present in the CC leaf were partially removed by the $\mathrm{NaOH}$ solution leading to an increased number of pores resulting in higher capacitance performance (Table 3). The activation time with $\mathrm{NaOH}$ significantly impacted the porous structure of the CC leaf. Higher the activation time, greater the size of the pores formed and lower the capacitance performance as the ion concentration in the separator was reduced. ${ }^{104} \mathrm{CC}$ leaves demonstrated to be a good candidate for separators in SCs.

Poli et al. fabricated easy-to-dispose SCs employing green raw materials; a step towards sustainable manufacturing and easy recycling. ${ }^{105}$ Electrospinning was performed at room temperature to produce a biodegradable pullulan separator. Carbon electrodes were prepared from pepper seed-waste and 1-ethyl-3-methyl-imidazoliumbis(trifluoro-methyl-sulfonyl)imide was used as an electrolyte. Such a SC delivered up to $27.8 \mathrm{~W} \mathrm{~h} \mathrm{~kg}^{-1}$ energy density and $5 \mathrm{~kW} \mathrm{~kg}^{-1}$ power density at $3.2 \mathrm{~V}$. Combining a hydrophilic separator with a hydrophobic ionic liquid electrolyte eases the task of separation of the components after the endof-life.

2.4.2. Egg shell based membranes. Avian egg shell membranes (ESMs) have been used to fabricate separator membranes as they are non-toxic, of low cost, abundantly available, biodegradable and have highly porous structures. They are stable in both alcoholic and aqueous media. ${ }^{106}$ The outer shell membrane of the ESM is commonly used for the fabrication of separators as it can be easily isolated from the egg shells. Separators have been fabricated from the egg shells of ducks (DESM), chicken (CESM) and goose (GESM) which were then employed in coin type SCs. ${ }^{107}$ The size and structure of fibres present in these egg shell based separators as well as the thickness of the separator have a profound effect on the performance of the SC. The CESM had a better capacitive and resistive performance as compared to the other membranes because of their smaller thickness (Table 2). Thinner ESMs also exhibited a higher value of specific capacitance. A study of the electrolyte adsorption showed that the DESM had the highest adsorption capacity of electrolyte $(\sim 133 \%)$ while the GESM had the lowest adsorption capacity of electrolyte ( $\sim 102 \%)$ (Fig. 7e). The size and shape of pores in ESMs can be influenced by the addition of titania $\left(\mathrm{TiO}_{2}\right)$. In order to study this effect, the DESM based separators were coated with varying concentrations of $\mathrm{TiO}_{2}$ nanoparticles using the dip coating method. ${ }^{108}$ $\mathrm{TiO}_{2}$ particles formed a coating on the duck eggshell fibres in DESM immersed in $1 \mathrm{wt} \%$ of $\mathrm{TiO}_{2}$ leading to the formation of a significant number of pores. In DESMs immersed in $5 \mathrm{wt} \%$ $\mathrm{TiO}_{2}$, the size of the pores reduced while the number of pores increased. At concentrations of $\mathrm{TiO}_{2}$ above $10 \mathrm{wt} \%$, the pores were found to get covered completely, reducing the specific capacitance from 2.3 to $0.035 \mathrm{~F} \mathrm{~g}^{-1}$ as shown in Table 2 .

ESM based separators exhibit excellent thermal stability, mechanical strength (tensile strength $=6.59 \mathrm{MPa}$ ) and electrochemical performance. ESMs of $0.8 \mathrm{~mm}$ thickness can sustain a maximum stress of $6.6 \pm 0.5 \mathrm{MPa}$ and a strain of $7 \pm 0.3 \%$ which is slightly lower when compared to commercially used polypropylene (PP) separators. ${ }^{109}$ They can also retain their properties at temperatures below $100{ }^{\circ} \mathrm{C}$ and degrade at temperatures above $220{ }^{\circ} \mathrm{C}$ thus indicating their excellent thermal stability. A comparison of the degree of water uptake and swelling revealed that it was higher in ESMs (10 and 8\%, respectively) as compared with that in PP based commercial membranes (3\%). SCs fabricated using ESM based separators display improvement due to low resistance, lesser relaxation time $(t \sim 4.76 \mathrm{~s}$ ), and splendid cyclic stability (more than $90 \%$ retention after 10000 cycles).

Apart from fabricating separators from egg shells, attempts have also been made to fabricate SCs entirely from materials derived from eggs. All solid-state, flexible SCs were successfully fabricated as shown in Fig. 7d. ${ }^{110}$ The electrodes were developed using $1.25 \mathrm{~nm}$ thick $2 \mathrm{D}$ graphene like egg derived carbon sheets as they exhibited exceptional power and energy densities owing to their high surface area of $1527 \mathrm{~m}^{2} \mathrm{~g}^{-1}$ and naturally doped functional groups. Egg white/yolk reacting with $\mathrm{KOH}$ was used as a gel like solid electrolyte while ESMs were used as separator membranes. The ESMs had an interwoven, macroporous network of fibres whose diameter ranged between 0.5 and $1 \mu \mathrm{m}$. The SC thus developed showed excellent flexibility as its specific capacitance remains unchanged on being subjected to bending and twisting. When two such SCs were connected in series, they were able to light up an LED for hundreds of seconds thus highlighting their potential for employment in practical applications. In another such attempt, bio-waste ESMs

Table 2 Comparison of specific capacitance obtained on using egg shell membranes as separators in SCs

\begin{tabular}{|c|c|c|c|c|c|c|}
\hline Egg shell membrane & Thickness (mm) & Average fibre diameter $(\mathrm{nm})$ & Current (mA) & Voltage (V) & Specific capacitance $\left(\mathrm{F} \mathrm{g}^{-1}\right)$ & Ref. \\
\hline $\mathrm{DESM}+1 \mathrm{wt} \% \mathrm{TiO}_{2}$ & - & - & 0.02 & 0.002 & 0.7 & 108 \\
\hline $\mathrm{DESM}+5 \mathrm{wt} \% \mathrm{TiO}_{2}$ & - & - & 0.007 & 0.002 & 2.3 & 108 \\
\hline $\mathrm{DESM}+10 \mathrm{wt} \% \mathrm{TiO}_{2}$ & - & - & -0.0021 & -0.004 & 0.035 & 108 \\
\hline DESM & 0.10 & 1.314 & - & 0.5 & 156.14 & 107 \\
\hline CESM & 0.03 & 1.177 & - & 0.5 & 159.22 & 107 \\
\hline GESM & 0.14 & 937 & - & 0.5 & 153.06 & 107 \\
\hline
\end{tabular}









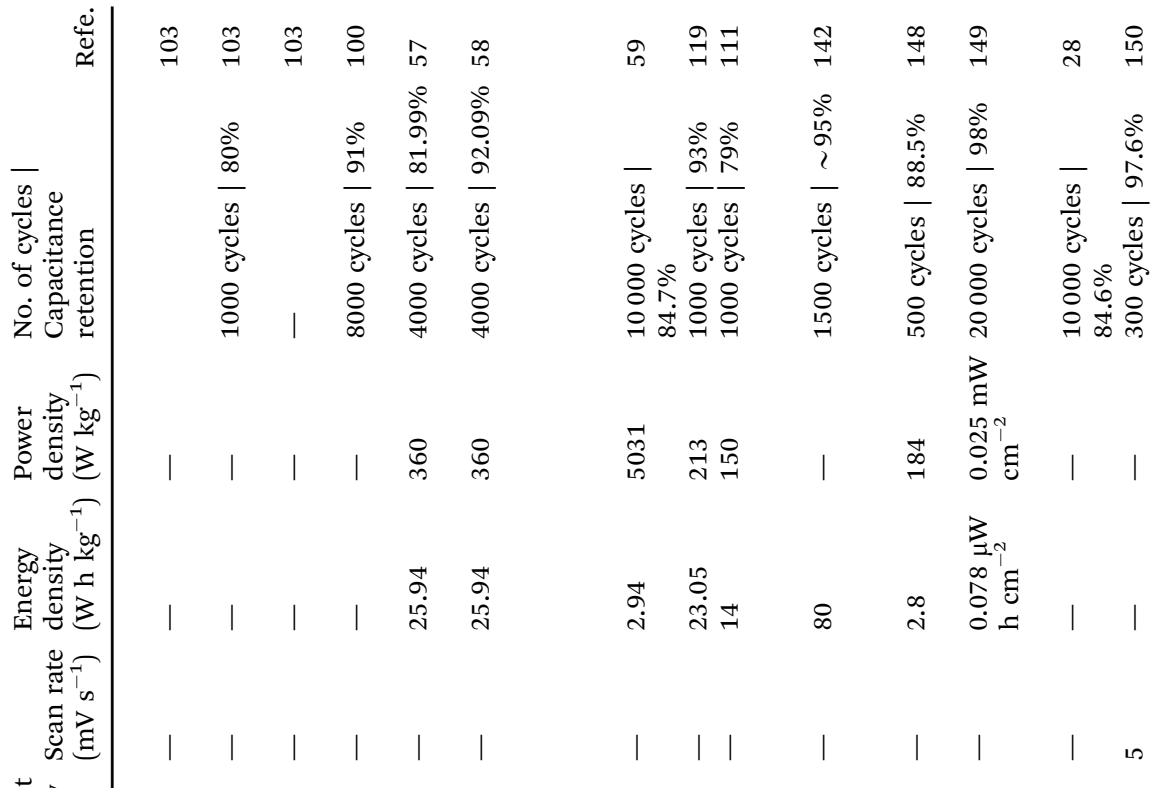



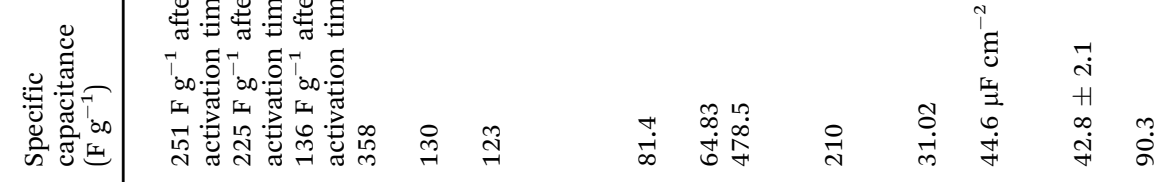

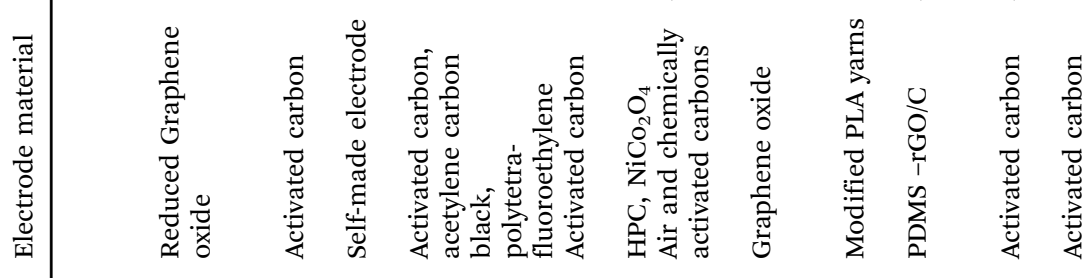

雚。

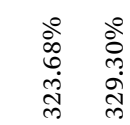

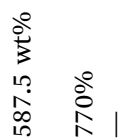

:

空芯

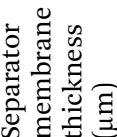

l 1 유 융

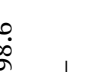

范

| त्र

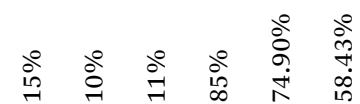

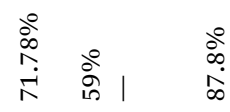

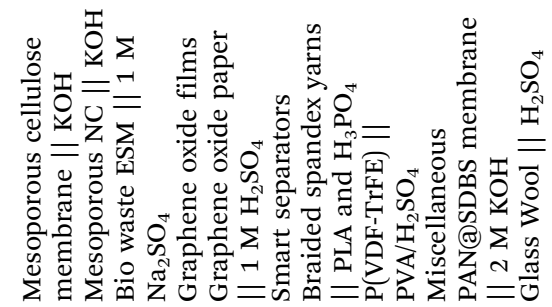


were used for the development of electrodes and separators to be employed in asymmetric SCs. ${ }^{111}$ Biomaterials when carbonized, oxygen and nitrogen can firmly be doped in the carbon structure. Such bio-derived carbon does not only offer an optimum pore size (size bigger than the microporous structure) for ion absorption/transport but also the additional pseudocapacitance due to the presence of $\mathrm{O}$ and N. ${ }^{112,113}$ The combination of air-activated ESM carbon as the cathode, $\mathrm{MnO}_{2}$ nanoparticle-chemically activated ESM carbon as the anode, and a natural ESM bio-separator displayed good electrochemical performance (Table 3) and showed a path for making renewable energy devices by utilizing biowaste materials.

2.4.3. Cellulose based membranes. Cellulose is an abundant polysaccharide found in nature in the form of wood, cotton, bamboo, etc. Their low cost, high flexibility, excellent thermal, mechanical and chemical stability, surface hydroxyl groups and good wettability make them ideal materials to be used as separators as well as electrodes for SCs. ${ }^{114}$ Recent research has focussed on the fabrication of flexible and transparent cellulose membrane as a separator using the phase inversion process as it is one of the most efficient techniques to fabricate meso/porous membranes. ${ }^{59}$ The mesoporous membrane formed in one such work exhibited better ionic conductivity and electrolyte uptake as compared to commercially available separators such as NKK-MPF30AC and NKK-TF4030 (Fig. 7f-i). When used as a separator in a SC, the specific capacitance, energy density and power density were also found to be superior as compared to those of SCs having commercially used separators. Porous cellulose separator films were fabricated using this process and the concentration of cellulose in the films was varied from $3 \mathrm{wt} \%$ to $9 \mathrm{wt} \%{ }^{57}$ The porosity and the electrolyte uptake of the separator film first increased and then decreased as the concentration of the cellulose increased in the solution. The tendency of cellulose to form agglomerates at high concentrations was responsible for the decrease in the values of these parameters. On the other hand, the Young's modulus and the ultimate tensile strength were found to increase with an increase in the cellulose concentration which was attributed to the intermolecular hydrogen bonding between hydroxyl groups present in the cellulose. The film with a cellulose concentration of $7 \mathrm{wt} \%$ (ACR-7) was found to be an ideal separator as it had a uniform mesoporous structure and a small pore size and also exhibited promising electrochemical and mechanical properties (Tables 1 and 3). Teng et al. also had very similar findings. They also observed that the contact angle of the separator films decreased with the increasing cellulose concentration. ${ }^{58}$ Apart from the phase inversion process, inkjet printing technology/ layer by layer method and non-contact methods were also employed to prepare cellulose separators for SCs. ${ }^{115,116}$

The use of nanocellulose (NC) in energy storage applications has gained increasing importance in recent years. NC has a high mechanical strength $(\sim 2-3 \mathrm{GPa})$ and Young's modulus $(\sim 110-140 \mathrm{GPa}) ;^{117,118}$ and a potential to fabricate separators as tightly controlled porous structures can be developed. ${ }^{11}$ Separators fabricated using pure NC get peeled off from the glass substrate upon drying due their poor adhesion with the glass. One can observe the bubble formation when chitosan is used as a separator over a glass substrate which offers an increased possibility of a short-circuit. In contrast, separators comprising 50\% NC and 50\% chitosan exhibited both good adhesion and no bubble formation. Chitosan plays a key role in such separators as a binder and an adhesion promoter for NC, thus eliminating the peeling off issue observed in separators fabricated from pure NC. The ionic conductivity of this separator film $\left(0.9 \mathrm{~S} \mathrm{~m}^{-1}\right)$ too is similar to that of pure NC separators $\left(1 \mathrm{~S} \mathrm{~m}^{-1}\right)$ and hence is advantageous from the manufacturing point of view.

NC was used in the fabrication of all nanofiber asymmetric SCs as shown in Fig. 7j. ${ }^{119}$ Hierarchical porous carbon (HPC) and $\mathrm{HPC} / \mathrm{NiCo}_{2} \mathrm{O}_{4}$ derived from forest based NC were used as electrodes and were found to contain 3D fibrilar network with an ultrahigh surface area of $2046 \mathrm{~m}^{2} \mathrm{~g}^{-1}$. The mesoporous NC membrane used as a separator facilitated faster ion as well as electron transfer, even with a thicker design of an ASC. The electrochemical functioning of the all nanofiber ASCs outperformed other NC based ASCs reported so far (Fig. 7k). The SC also reported promising electrochemical properties (Table 3).

Bacterial cellulose (BC), a type of $\mathrm{NC}$, has also shown tremendous potential in the fabrication of separators. ${ }^{120}$ This was observed by $\mathrm{Lv}$ et al., who fabricated a flexible, ASC (thickness $\sim 15 \mu \mathrm{m}$ ) having an integrated electrode-separator. ${ }^{121}$ The in situ deposition of layers of PANI-BC//BC// $\mathrm{KPBC}(\mathrm{KOH}$ activated pyrolysis PANI/BC)-CNT formed the cell. As the 3D interconnected network of $\mathrm{BC}$ was used as a matrix of integral electrode-separator, the solution resistance was only $2.48 \Omega$ at $1 \mathrm{~mol} \mathrm{PVA} / \mathrm{H}_{2} \mathrm{SO}_{4}$ electrolyte. Promising electrochemical properties such as a maximum volumetric capacitance of $28.3 \mathrm{~F} \mathrm{~cm}^{-3}$ with $100 \%$ capacitance retention even after 2500 cycles at a current density of $0.1 \mathrm{~A} \mathrm{~g}^{-1}$ were exhibited by this ASC.

2.4.4. Paper based membranes. Paper separators have been used on an industrial scale along with organic solvents as electrolytes. ${ }^{130}$ They can also be used to fabricate films and aerogels possessing large surface area, high porosity and high mechanical strength. ${ }^{131,132}$ Symmetric SCs comprising a cellulose paper-based separator with thickness $50 \mu \mathrm{m}$ and two cellulose paper/RGO electrodes were manufactured by Koga et al. ${ }^{133}$ The stand out features of this green SC were that it was light in weight, cheap, portable and completely based on recycled cellulose obtained from newspapers and could have the potential to be employed in wearable energy storage devices. To study the influence of separator thickness on the cell resistance, filter paper sheets were used as separators in SCs. ${ }^{134}$ The size of the separator in the SC was varied by altering the number of sheets used, each of which was $0.15 \mathrm{~mm}$ thick and had a pore size of $15 \mu \mathrm{m}$. The cell resistance was found to increase linearly by 1.5 to $1.6 \Omega \mathrm{mm}^{-1}$ as the separator thickness was increased. This was attributed to resistance offered by the pores in the sheets. Commercial paper substrates coated using SWCNT inks were also used to prepare fully integrated printed SCs. ${ }^{135}$ The surface of the paper was initially treated with PVDF in order to produce a thin layer without large holes 
enabling only the transport of the electrolyte through the paper. This was followed by a coating of SWCNT ink on either side of the paper. The SWCNT coating performed the dual role of the electrodes and current collector while the paper behaved as both the substrate and the separator. The authors reported a specific capacitance of $33 \mathrm{~F} \mathrm{~g}^{-1}$ and a very small loss in specific capacitance after 2500 charge-discharge cycles. A major drawback that has hindered the use of paper separators in SCs is its accelerated ageing in water solvents as well as its degradation when used with $\mathrm{H}_{2} \mathrm{SO}_{4} \cdot{ }^{136,137}$

\subsection{Graphene oxide films}

Graphene oxide (GO) films have a morphology distinct from that of macro-porous materials which are commonly used to fabricate separators. Dry GO films are not electrically conducting and instead need a water or a water-based electrolyte to become electrically conducting. The level of oxidation in individual GO films also has a major influence on its electrical conductivity. ${ }^{138}$ Highly oxidized GO films are the most suitable to be used as separators and were successfully employed by Shulga et al. in SCs having a layered PANi/GO/PANi structure. The SC developed reported a capacity of $150 \mathrm{~F} \mathrm{~g}^{-1}$ and was capable of retaining its capacity by $90 \%$ after 1500 cycles. On replacing the wetting medium around the membrane from $\mathrm{H}_{2} \mathrm{O}$ to $\mathrm{D}_{2} \mathrm{O}$ (deuterium oxide), a 1.46 fold increase in the current flowing through the GO membrane was observed, indicating the effect of proton type on the conductivity of the GO separator. ${ }^{139,140}$ GO membranes were also successfully used as separators $(\sim 15 \mu \mathrm{m}$ thick $)$ along with GO reduced by microwave exfoliation (MEGO) as electrodes in the fabrication of metal free SCs. ${ }^{141}$

Graphene oxide papers (GOP) developed by separating thicker GO films from substrates are found to have unique membrane properties such as excellent mechanical strength, etc. The properties of GOP as a separator were further explored by using them in SCs with MEGO as electrodes. ${ }^{142}$ The porous structure of the separator was studied using the standard contact porosimetry (SCP) method with octane and water as the testing media. The separator swelled up significantly to about three times its original width in the presence of water but did not swell up in the presence of octane. The swelling up of the dry membrane when immersed in water resulted in the increase in porosity of the membrane from $1.47 \mathrm{~cm}^{3} \mathrm{~g}^{-1}$ to $2.64 \mathrm{~cm}^{3} \mathrm{~g}^{-1}$. An increase in the volume of micro pores $(r<1 \mathrm{~nm})$, middle sized pores $(1 \mathrm{~nm}<$ $r<1000 \mathrm{~nm})$ and the specific surface area $\left(648 \mathrm{~cm}^{2} \mathrm{~g}^{-1}\right.$ to $2170 \mathrm{~cm}^{2} \mathrm{~g}^{-1}$ ) and a decrease in the volume of macropores $(r>1000 \mathrm{~nm})$ were also observed. The value of porosity in the GOP was found to be $87.8 \mathrm{vol} \%$. The SCs developed had excellent electrochemical properties such as a capacity of $200 \mathrm{~F} \mathrm{~g}^{-1}$ and an energy density of $80 \mathrm{~W} \mathrm{~h} \mathrm{~kg}{ }^{-1}$. GOP when impregnated with water or water solutions of acids had similar properties such as high porosity, surface area and protonic conductivity to that of commercially used Nafion membranes.

\subsection{Metal organic frameworks}

Metal organic frameworks (MOFs) have attracted the attention of researchers due to their possible application in next generation energy storage technologies. They mainly comprise metal nodes and organic linkers and exhibit unusual yet exceptional properties such as high porosity and surface area, good thermostability and uniform cavities. These properties along with conductivity can be tuned according to the application the MOF is used in. Hence, a majority of researchers employed MOFs in making electrodes for batteries and supercapacitors. ${ }^{143}$ The properties such as pore size and topology can be varied based on the selection of appropriate linkers and nodes. Some studies have been reported in the recent past wherein MOF separators were used in batteries are but hardly in supercapacitors. ${ }^{14-146}$ In one such work of separator membranes in SCs, two thermally stable MOFs namely CoL(1,4-bdc). $2 \mathrm{DMF}$ as MOF1 and $\mathrm{CdL}\left(4,4^{\prime}\right.$-bpc).3DMF as MOF2 were fabricated. ${ }^{147}$ The MOF1 displayed the formation of large channels with a non-interpenetrated network while MOF 2 exhibited a highly interpenetrating network structure with a small pore size. Both MOFs when employed as separators in SCs and charged/discharged at high current density, displayed much smaller specific capacitance in comparison with the blank SCs. This was due to large impedance drawn by these materials for not being electro-conductive. But at a small current density $\left(\sim 0.2 \mathrm{~A} \mathrm{~g}^{-1}\right)$, separator MOF1 showed nearly three times larger specific capacitance $\left(66.7 \mathrm{~F} \mathrm{~g}^{-1}\right)$ than the blank SC $\left(23.2 \mathrm{~F} \mathrm{~g}^{-1}\right)$ due to promotion of ionic diffusion (probably due to the faradaic redox current produced by cobalt oxide in the separator) and the charge transfer process (due to more porous morphology). Even though a clear mechanism is not understood, it displayed that the right choice of an MOF with suitable functional and structural tunability changes the electrochemical performance of the SC positively.

\section{Separators for micro-supercapacitors}

Planar (2D) micro-supercapacitors (MSCs) can be fabricated either with a sandwich or an inter-digitated structure. In a sandwich structure MSC, a separator is placed between the two electrodes with the electrolyte before assembling and packaging. ${ }^{151}$ Separators must be chemically resistant to corrosion induced by electrolytes and electrode degradation by-products. The commonly used separator materials are cellulose-based or polyolefin-based polymers such as polypropylene (PP), polyethylene (PE), Teflon, PVDF, and PVC. ${ }^{152,153}$ However, sandwiched MSCs have limitations due to the possibility of a short circuit or position dislocation of electrode films. Additionally, the thick separator layer invariably increases ion transport resistance, resulting in rapid specific capacitance degradation and low power density. ${ }^{154,155}$ On the other hand, interdigitated planar MSCs comprise interdigital electrode fingers separated by nano/micrometer size interspaces eliminating the need for a separator. It allows high active loading on each electrode and exposes more area at the electrolyte interface. The absence of a separator allows fast ion diffusion in the electrode and electrolyte surfaces, enhancing the specific capacitance of the MSC. ${ }^{156}$ 
Cellulose-based membranes as separators have been extensively investigated for MSCs. Furthermore, membranes having self-healing properties may extend the life of the electrolyte separator. $^{157} \mathrm{Li}$ et al. ${ }^{158}$ developed a flexible double-crosslinked cellulose-based hydrogel membrane as an alternative for conventional polymer separators. They used poly-dopamine (PDA) as a cross-linker between rigid cellulose and flexible polyacrylamide (PAM) networks. The effect of cellulose and DA on the characteristics of hydrogels was investigated by producing hydrogels $\left(\mathrm{C}_{n}-\mathrm{DM}-x\right)$ with various cellulose contents $(n)$ and DA/ $\mathrm{AM}$ ratios $(x)$. The mechanical and self-healing properties of the $\mathrm{C}_{4}$-DM-40 ( $4 \%$ cellulose- $40 \mathrm{wt} \%$ of DA/AM) hydrogel were found to be superior compared to those of other hydrogels. The MSC electrode fabricated by directly depositing activated carbon materials on the $\mathrm{C}_{4}$-DM-40 hydrogel membrane presented an areal capacitance of $275.8 \mathrm{mF} \mathrm{cm}^{-2}$ and a volumetric capacitance of $394.1 \mathrm{~F} \mathrm{~cm}^{-3}$ at a scan rate of $10 \mathrm{mV} \mathrm{s}^{-1}$.

For stretchable MSCs, solely the gel electrolyte as a separator fails to prevent the device from dislocating and short circuits when subjected to an external force due to the poor interaction between the internal molecules. ${ }^{159}$ The manufacturing of commercial polyolefin separators is easy but have poor ionic conductivity because of their small volume porosity and pore size. As a result, an effective strategy is needed to meet the stretchability of the device, with a simplified fabrication process considering large-scale applications. Laser direct writing (LDW) with arbitrary pattern cutting can precisely edit the electrodes and separator, allowing the negative Poisson's ratio (NPR) structure to be transferred into the MSC. ${ }^{160}$ Yan et al. ${ }^{161}$ used electrospinning and LDW methods to develop asymmetric MSCs with NPR structures and polyacrylonitrile (PAN) nanofiber separators. The separator was then coated with the gel electrolyte and assembled with two composite electrodes composed of carbon nanofibers and nanoarrays (CNF@ $\mathrm{Fe}_{2} \mathrm{O}_{3}$ nanorods and $\mathrm{CNF} @ \mathrm{MnO}_{2}$ nanosheets).

The conductivity of GO depends on the environment and it ranges between $5 \times 10^{-6} \mathrm{~S} \mathrm{~cm}^{-1}$ and $4 \times 10^{-3} \mathrm{~S} \mathrm{~cm}^{-1},{ }^{162}$ indicating that GO is almost electrically insulating. When a significant amount of water is entrapped in the layered GO structure, it transforms into a strong anisotropic ionic conductor as well as an electrical insulator, allowing it to be used as an electrolyte and electrode separator. ${ }^{163}$ Gao et al. ${ }^{164}$ utilized direct laser reduction for patterning of hydrated GO films to develop a new type of all-carbon MSC. The electrodes were made from the laser-patterned part of the GO film (rGO). When high-intensity light was absorbed by GO, it was transformed to graphene, and the hydrated GO between the electrodes functioned as a MSC separator.

\section{Smart separators}

The biggest challenge with the energy storage devices used for electronic applications is the continuous supply of energy for longer time-period, leading to its frequent recharging. To fulfil the requirements of electronic devices for next generation, portable and lightweight self-powered systems such as selfcharging SCs are developed which are capable of converting mechanical energy into electrochemical energy through piezoelectric activity. One such flexible piezoelectric self-charging SC (PSCS) stuck to a human finger was fabricated using a piezoelectric material $\mathrm{P}(\mathrm{VDF}-\mathrm{TrFE})$ film and $\mathrm{PVA} / \mathrm{H}_{2} \mathrm{SO}_{4}$ as a gel electrolyte (Fig. 8a and b). ${ }^{149}$ The film performed the dual role of a separator and a potential nano-generator in the SC. It formed a network like structure with nanofibers of diameter $200 \mathrm{~nm}$ and lengths ranging in several tens of micrometres. An initial voltage of $-0.15 \mathrm{~V}$ was observed when the human finger was flat which further increased to $0.05 \mathrm{~V}$ and $0.45 \mathrm{~V}$ when the human finger was bent at $30^{\circ}$ and $90^{\circ}$ respectively. The piezo electric field of the $\mathrm{P}(\mathrm{VDF}-\mathrm{TrFE})$ film was responsible for driving the $\mathrm{H}^{+}$and $\mathrm{SO}_{4}{ }^{2-}$ ions towards the positive and negative electrodes when deformation was applied. The increase in the potential window was proportional to the stress applied on the PSCS device. On relaxing the finger from $30^{\circ}$ and $90^{\circ}$, the discharge time was found to be 4 and 18 seconds, respectively, thus confirming the self-charging ability of the PSCS device. Apart from promising electrochemical properties (Table 3), a stable discharge current of $6.4 \mu \mathrm{A}$ further reinforces its potential to be used in future wearable micro electronic devices. A similar selfcharging ASC was developed having a bio-piezoelectric separator (BPES). ${ }^{165}$ A porous fish bladder was used as the BPES which was soaked in a PVA-KOH gel electrolyte. The SC could be charged either by imparting mechanical deformations such as finger pressing, heel pressing, etc. or by electrical charging. In a period of 80 seconds, the SC could be charged up to $281.3 \mathrm{mV}$ just by human finger imparting at a frequency of $1.65 \mathrm{~Hz}$. The specific capacitance of the SC was found to be $165 \mathrm{~F} \mathrm{~g}^{-1}$ at a current density of $1 \mathrm{~A} \mathrm{~g}^{-1}$ which slightly decreased with an increase in the current density as seen in Fig. 8f. Fig. 8c and d represent the CV curves of the SC under different conditions including varied applied pressures, sole shoe pressing and elbow bending at different angles. The SC was able to retain $82.2 \%, 80.8 \%$ and $77 \%$ of its initial specific capacitance under heel pressing, finger imparting and twisted mode at $20 \mathrm{~A} \mathrm{~g}^{-1}$. A plot of specific capacitance $v s$. current density of the SC under various bending and twisting modes can be seen in Fig. 8e. It was also reported that eight such SCs connected in series can power portable electronic devices too. Apart from self-charging SCs, Kirigami paper based flexible SCs were designed for powering wearable electronic devices due to their high stretch-ability $(\sim 210 \%)$ and mechanical durability ( $\sim 2000$ loading/unloading cycles). ${ }^{166}$

New trends have also led to the development of one-step 'energy harvesting and storage' devices by integrating smart materials (separators) with batteries/SCs to reduce unnecessary energy loss. ${ }^{167,168}$ A hybrid piezo-SC, integrating an energy harvesting film with an SC, was fabricated without any rectification device by Song et al. ${ }^{169}$ Herein, the flexible PVDF film, which acted as a separator as well as an energy harvester, was used to convert mechanical vibrations into a built-in electric field. This electric field served as a driving force for the migration of the ions through the PVA electrolyte towards the interface of functionalized carbon cloth electrodes (Fig. $8 \mathrm{~g}$ and $\mathrm{h}$ ). 
(a)

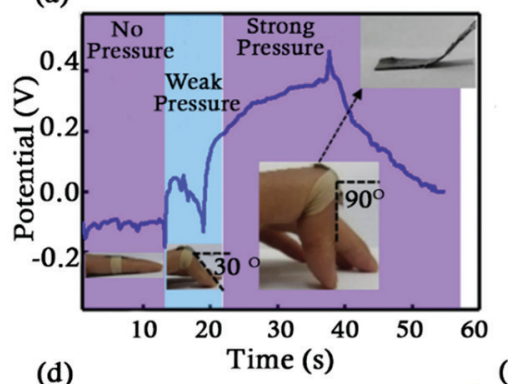

(d)

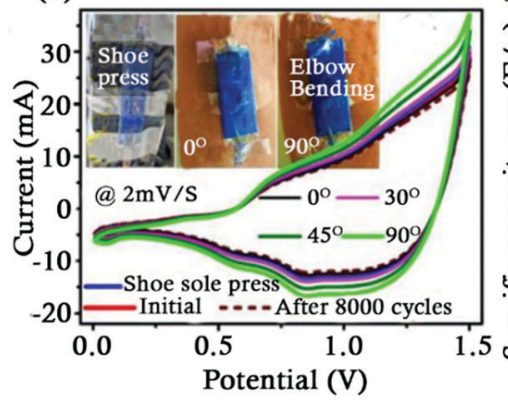

(g)

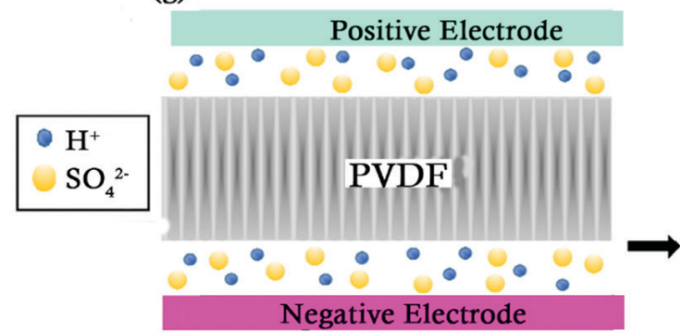

(i)

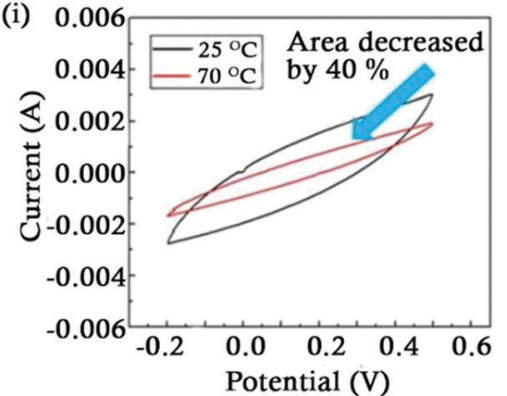

(b)

(e)
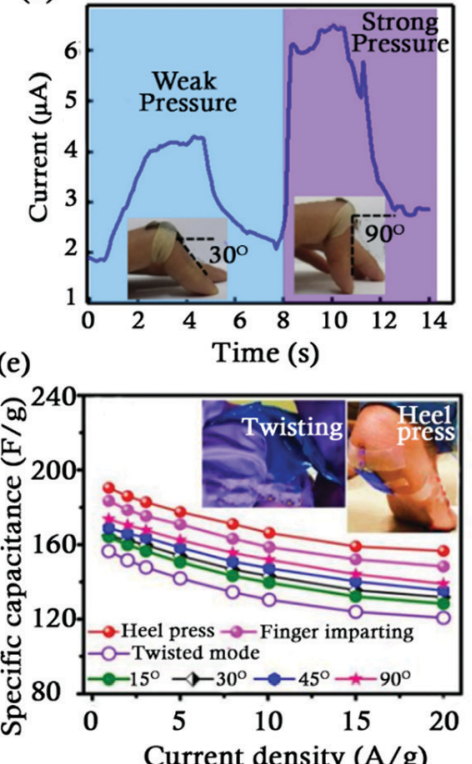

(c)

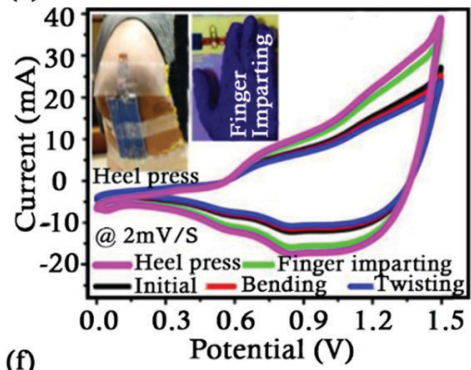

(f)

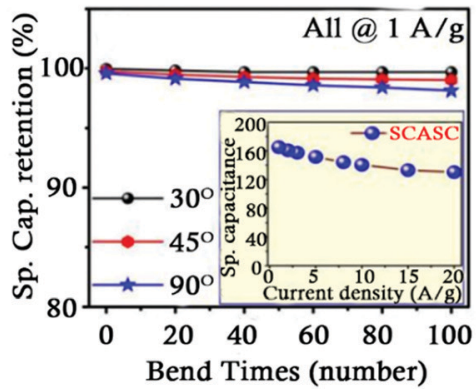

(h) Compressive Force

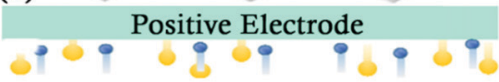

$\mathrm{v}+\mathrm{v}+\mathrm{V}+\mathrm{v}+\mathrm{v}+\mathrm{V}+\mathrm{v}+\mathrm{v}+\mathrm{v}+\mathrm{v}+$

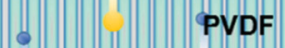

$V_{-} V_{-} V_{-} V_{-} V_{-} V_{-} V_{-} V_{-} V_{-} V_{-}$

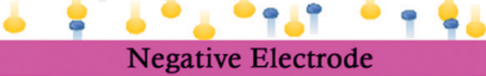

(j)

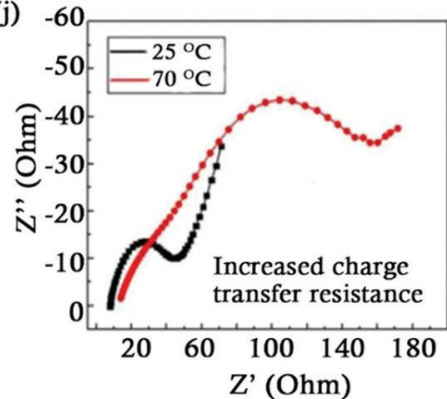

Fig. 8 (a) Charge discharge curve of the PSCS (b) Short circuit current curve at different bending angles of the PSCS. Reproduced with permission. ${ }^{149}$ CV profile of the device (c) under various conditions, (d) under shoe sole pressing and elbow bending. Plots of (e) specific capacitance vs. current density and (f) specific capacitance retention vs. number of bending times. Reproduced with permission. ${ }^{165}$ (g) Hybrid piezo-SC's working mechanism. (h) Electrochemical and piezoelectric potential at equilibrium. Reproduced with permission. ${ }^{169}$ (i) Cyclic voltammetry $\left(0.5 \mathrm{~V} \mathrm{~s}{ }^{-1}\right)$ and (j) Nyquist plot of trilayered-PNIPAM under 25 and $70{ }^{\circ} \mathrm{C}$. Reproduced with permission. ${ }^{184}$

Such a flexible SC demonstrated a high specific capacitance of $357.6 \mathrm{~F} \mathrm{~m}^{-2}$ even during bending and stretching along with stable electrochemical performance with a power density and an energy density of $400 \mathrm{~mW} \mathrm{~m}^{-2}$ and $49.7 \mathrm{~mW} \mathrm{~h} \mathrm{~m}^{-2}$, respectively.

Fibre shaped stretchable SCs have gained attention lately as they can achieve high levels of strain and three-dimensional flexibility. This enables them to be integrated into microelectronics or even to be woven into cloth. However, there are certain limitations to the length and number of fibre electrodes that can be incorporated in a SC. ${ }^{170,171}$ Another major challenge is maintaining high stretchability of the SC while simultaneously avoiding contact between the inner and outer electrodes. ${ }^{172}$ Nie et al. developed cord shaped stretchable SCs with layer by layer braiding. ${ }^{148}$ The inner and outer electrodes are comprised of 6 modified PLA yarns each while the separator is comprised of 12 spandex monofilament yarns. Spandex monofilament yarns of 3 different diameters $(0.5 \mathrm{~mm}$, $0.3 \mathrm{~mm}$ and $0.1 \mathrm{~mm}$ ) were used as separators in different samples in order study their influence on the mechanical and electrochemical properties of SCs. These spandex monofilament 
yarns were braided onto the surface of the inner electrodes (modified PLA yarns) while the outer electrodes (modified PLA yarns) were braided onto the surface of the monofilament spandex yarns. The braiding was carried out in such a way as to avoid contact between the inner and the outer electrodes. Smaller was the diameter of the spandex monofilament yarns, better was the energy storage performance observed, attributed to the increase in its porosity. An analysis of the area enclosed in the CV curves showed that the optimal length of the SC was $20 \mathrm{~mm}$ and the diameter of the spandex monofilament used for the braiding of separator was $0.1 \mathrm{~mm}$.

Traditionally used SCs are able to withstand temperatures up to $100{ }^{\circ} \mathrm{C}$. The commercially used separators in these SCs, fabricated using polymers and cellulose papers, undergo shrinkage and deformation at temperatures above $80{ }^{\circ} \mathrm{C}$, making them unreliable to be used for high temperature applications. ${ }^{173,174} \mathrm{An}$ increase of $10{ }^{\circ} \mathrm{C}$ can accelerate the ageing of the SC by a factor ranging anywhere between 1.7 and 2.5. ${ }^{175}$ Development of SCs that can be used for high temperature applications $\left(>120{ }^{\circ} \mathrm{C}\right)$ such as oil drilling, military and for devices used in outer space is gearing up. ${ }^{176,177}$ A major cause of accumulation of heat within SCs is due to thermal runaway mainly due to overcharging, overheating, electrolyte decomposition, mechanical shocks, etc. This results in severe consequences such as reduction in cycle life and performance, hazardous fires, etc. ${ }^{178,179}$ An effective way to reduce the thermal runaway is by breaking the thermal loop caused by undesired electrochemical reactions at high temperatures. With an aim to control the capacitive behaviour at elevated temperatures and break the electrochemical reaction, researchers developed temperature responsive polymers which can manipulate ion migration and adsorption by changing its conformation or physical properties like viscosity with temperature. ${ }^{180-182}$ They have the ability to sense temperature and are reversible once they return to room temperature. ${ }^{183}$ Jiang et al. developed temperature responsive separators by casting poly( $N$-isopropylacrylamide) (PNIPAM) into thin films of varying thicknesses $(20,40$ and $60 \mu \mathrm{m})$ which were then sandwiched between polypropylene to form a SC. ${ }^{184}$ PNIPAM possesses a lower critical solution temperature (LCST) of $32{ }^{\circ} \mathrm{C}$, below which they are hydrophilic, and shift towards the hydrophobic state at higher temperatures. Due to this property, ions can easily migrate between the electrodes at room temperature but would face higher resistance during migration at temperatures above the LCST due to steric hindrance of solvated ions. Fig. 8j displays that the charge transfer resistance increased suddenly above room temperature as PNIPAM precipitated at high temperatures, causing blockage of pores in PP films, resulting in reduced ion migration. This led to a reduction in both the capacitance of the SCs and the redox reactions taking place at high temperatures. A $40 \%$ reduction in the capacitance of the SC with a $60 \mu \mathrm{m}$ thickness separator from $375 \mathrm{mF} \mathrm{g}^{-1}$ at $25{ }^{\circ} \mathrm{C}$ to $221 \mathrm{mF} \mathrm{g}^{-1}$ at $70{ }^{\circ} \mathrm{C}$ was observed (Fig. 8i). Thicker PNIPAM layers offered greater hindrance during ion migration leading to a greater capacitance reduction. This was attributed to the more tortuous path ions would have to take as well as the hindrance they would encounter in thicker polymer films. A greater capacitance reduction was also reported at higher scan rates $\left(-20 \%\right.$ at $0.1 \mathrm{~V} \mathrm{~s}^{-1}$ to $-45 \%$ at $\left.1 \mathrm{~V} \mathrm{~s}^{-1}\right)$. This technique can be used to control the degree of reduction of capacitance at elevated temperatures and return back to normal functioning at room temperature according to the application.

\section{Influence of the separator material, wettability and electrolyte concentration on the performance of SCs}

The properties as well as concentration of the electrolyte have a major influence on the energy density and capacitance value of SCs. ${ }^{185}$ It has been observed that at higher electrolyte concentrations, SCs exhibit a higher specific capacitance and higher energy densities. ${ }^{185-187}$ However, many conventional separators (cellulose-based) are not capable of resisting highly concentrated electrolytes, such as $\mathrm{H}_{2} \mathrm{SO}_{4}$. Corrosion resistant materials such as fibreglass, polypropylene and glass wool have been used as a separator material in the past (Table 3). ${ }^{188-191}$ The performance of glass wool separators under various concentrations of the $\mathrm{H}_{2} \mathrm{SO}_{4}$ electrolyte was compared with that of conventional cellulose based separators by Yaacob et al. ${ }^{150} \mathrm{CV}$ analysis showed that the SC employing a glass wool separator even at low concentrations $\left(1 \mathrm{~mol} \mathrm{dm}{ }^{-3}\right)$ of the $\mathrm{H}_{2} \mathrm{SO}_{4}$ electrolyte displayed higher specific capacitance $\left(90.3 \mathrm{~F} \mathrm{~g}^{-1}\right)$ compared to the SC containing a cellulose based separator $\left(68.8 \mathrm{~F} \mathrm{~g} \mathrm{~g}^{-1}\right)$ at the same scan rate. This was attributed to the higher porosity of glass wool due to which higher amounts of liquid electrolyte can be held. ${ }^{47} \mathrm{~A} 40 \%$ increase in the specific capacitance $\left(120 \mathrm{~F} \mathrm{~g}^{-1}\right)$ of the SC with glass wool separators was observed on increasing the concentration of the $\mathrm{H}_{2} \mathrm{SO}_{4}$ electrolyte (from 1 to $18 \mathrm{~mol} \mathrm{dm}^{-3}$ ), indicating its dominance as a separator to achieve superior performance.

The influence of the wettability of the separator and the material with which it is fabricated on the SC performance was highlighted by Liivand et al. ${ }^{192}$ SCs were fabricated using four different separators (two commercial ones made from cellulose and polypropylene (Celgard 2400) and two self-made separators fabricated by electrospinning PVDF with varying surface morphologies) in three different electrolytes. At low temperatures and high scan rates, a poorly wetted separator limited the capacitive behaviour. In contrast, when the separator material was completely wet, the maximum capacitance was weakly dependent on the material of the separator membrane. Numerous other factors such as phase angle, specific power and characteristic relaxation time constant were found to depend on the characteristics of the separator material (chemical composition and surface morphology) through the impedance data.

Electrolytes also play a critical role in determining the operational voltage of SCs and have an influence on their energy density. Neutral aqueous electrolytes such as $\mathrm{Na}^{+}, \mathrm{Li}^{+}$, 
(a)



(c)

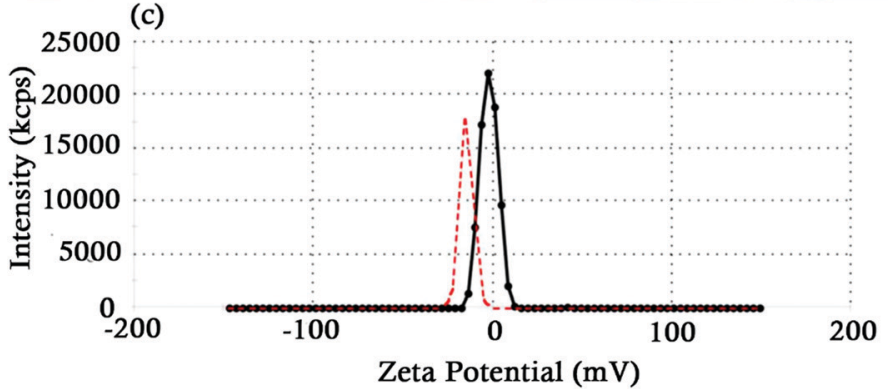

(b)
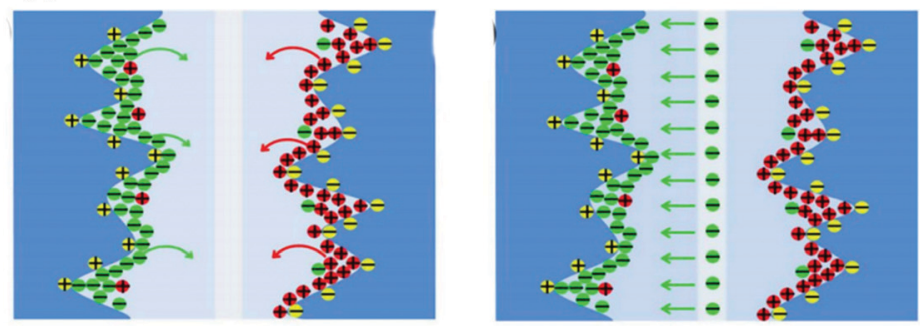

(d)

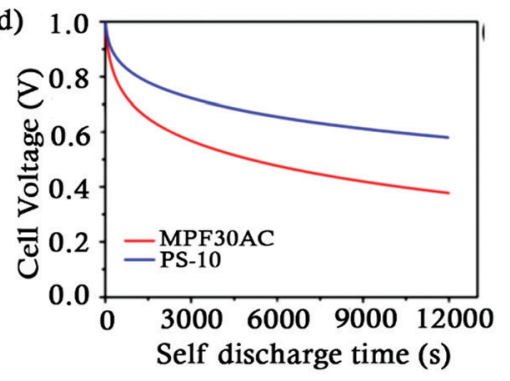

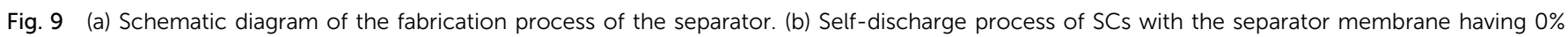

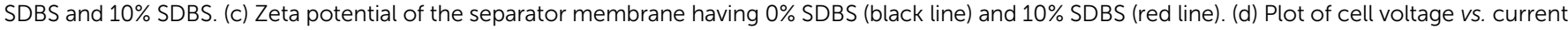
discharge. Reproduced with permission. ${ }^{28}$

and $\mathrm{K}^{+}$solutions are the preferred one for use in SCs over acidic and alkaline solutions because of their higher operating voltages. A di-sulfonated poly(arylene ether sulfone) (SPAES)/PEO composite separator membrane was employed along with a neutral aqueous lithium sulphate $\left(\mathrm{Li}_{2} \mathrm{SO}_{4}\right)$ electrolyte with varying mass fractions of PEO (10 wt\% to $60 \mathrm{wt} \%) .{ }^{55}$ The SC having a SPAES/PEO-50 wt\% separator membrane exhibited a high energy density of $19.04 \mathrm{~W} \mathrm{~h} \mathrm{~kg}^{-1}$ at a current density of $0.1 \mathrm{~A} \mathrm{~g}^{-1}$ which was attributed to the wide operating voltage range of $\mathrm{Li}_{2} \mathrm{SO}_{4}(2.2 \mathrm{~V}$ ) (Table 3). The electrolyte uptake of the SPAES/PEO composite membrane (161\% in the SPAES/PEO-60 wt\% separator membrane) increased while the mechanical properties such as tensile strength and 'elongation at break' decreased with the increasing concentration of PEO in the composite membrane (Table 1).

As SCs are widely being used as energy storage devices, it is essential that they have low self-discharge rates. Self-discharge in EDLCs can be attributed to a variety of reasons. Some of them are as follows: (a) redox reactions taking place in the electrodes and electrolytes due to overcharging and (b) charge redistribution in SCs taking place over a period of time which returns it to a steady state. ${ }^{193,194}$ Many authors have attempted to solve the charge-discharge problem. ${ }^{195,196}$ Peng et al. developed environment friendly separators from nanofiber membranes prepared using coaxial spinning of polyacrylonitrile (PAN) which was coated by varying concentrations of sodium dodecyl benzene sulfonate (SDBS) (0 to $15 \mathrm{wt} \%$ ) in order to study the effect of the microstructure of the nanofibers on the self-discharge behaviour of the separator. ${ }^{28}$ (Fig. 9d) During the study of the surface morphology of the nanofibers, the authors observed that the nanofibers prepared without SDBS were rougher as compared to those prepared with SDBS $(5 \%, 10 \%$, $15 \%)$. The SDBS also played a key role in reducing the surface tension of the fibre. The authors also observed that the SCs with $0 \%, 5 \%, 10 \%$ and $15 \%$ SDBS were able to retain a capacitance of $60.7 \%, 69.0 \%, 75.7 \%$, and $66.0 \%$ respectively. The authors speculated that the self-discharge in SCs with the PAN@SDBS membrane was supressed as follows. In fully charged SCs having separator membranes with $0 \%$ SDBS, the ions from the electrolyte accumulate on the surface of the electrodes. Ion migration takes place from the surface of the electrode to the electrolyte under open circuit conditions leading to a drop in the voltage. However, in SCs with the separator membrane having $10 \%$ SDBS, the $\mathrm{Na}^{+}$on the separator enters into the $\mathrm{KOH}$ electrolyte solution. Due to this, the separator membrane is negatively charged and repels the anions in the diffusion layer on the positive electrode as seen in Fig. 9a. The zeta potential test also revealed the fact that the membrane with $10 \%$ SDBS was indeed negatively charged in the alkaline solution, supporting the theory as displayed in Fig. 9b. Similar suppression of cations on the positive electrode was observed which was attributed to the lack of charge compensation of the anion. ${ }^{27}$ This leads to a suppression in the migration of ions, thus supressing the self-discharge (Fig. 9c). Such membranes fabricated by the coaxial electrospinning method were costing approximately $\$ 40 \mathrm{~m}^{-2}$, much less than Nafion cation exchange membranes $\left(\$ 800 \mathrm{~m}^{-2}\right)^{197}$ and NKK-MPF30AC $\left(\$ 54 \mathrm{~m}^{-2}\right)$ membranes.

\section{Conclusions}

Separators in SCs enable free ionic flow and isolate electronic flow. The design and fabrication decide the structure and properties of separators which in turn play a vital role in determining the performance of a SC including energy and 
power densities by regulating the cell kinetics, cycle life and safety. The material that exhibits high specific surface area, excellent mechanical properties and high thermal stability, serves as an electrolyte reservoir, remains electrochemically inert in a higher potential range, shows good cycling stability with high capacity retention, and allows easy and cheaper fabrication can be considered as an ideal separator material, whereas the process that can not only create nano-pores with controlled pore structures in a simple and efficient way on a large scale but also separate the electrodes and facilitate ion transport can be the ideal fabrication process. Retaining the desired mechanical properties with controlled pore structure is the key.

The characteristics (its chemical composition and morphology) of separator membranes influence the equivalent series resistance (depends on porosity and thickness), wettability (phase angle) and power density (relaxation time constant) of the SCs. High porosity (high specific surface area) is demanded in the design of separators to ensure plentiful electrolyte retention and continuous, rapid movement of ions back and forth between the electrodes.

To achieve longer service life and enhance the safety and thermal stability of SCs, thermal runaway can be reduced by employing temperature responsive polymers/separators which can manipulate ion migration and adsorption by changing their conformation or physical property like viscosity with temperature. Depending on the application involved, separators are expected to carry the load as they are integrated with the structural members, withstand low/high temperature without compromising with its required characteristics, and function as a multitasking component e.g. sometimes as diodes along with separating electrodes. Research analysis shows that a search for new nano based separators, smart separators and novel processing techniques is needed to enhance the performance of SCs under odd conditions as well. Apart from the improved power performance, a step towards the use of cheaper, non-toxic, biodegradable/low carbon footprint/green materials and achieving sustainable manufacturing of separators/SCs and their recycling is needed.

\section{Conflicts of interest}

There are no conflicts to declare.

\section{References}

1 J. Jose, V. Thomas, V. Vinod, R. Abraham and S. Abraham, J. Sci. Adv. Mater. Dev., 2019, 4, 333-340.

2 K. W. Tan, S. K. Heo, M. L. Foo, I. M. L. Chew and C. K. Yoo, Sci. Total Environ., 2019, 650, 1309-1326.

3 P. Simon and Y. Gogotsi, Nature Materials, World Scientific Publishing Co., 2008, vol. 7, pp. 138-147.

4 M. M. Pérez-Madrigal, M. G. Edo and C. Alemán, Green Chem., 2016, 18, 5930-5956.

5 J. Cao, Y. Zhao, Y. Xu, Y. Zhang, B. Zhang and H. Peng, J. Mater. Chem. A, 2018, 6, 3355-3360.
6 Y. Huang, Y. Zeng, M. Yu, P. Liu, Y. Tong, F. Cheng and X. Lu, Small Methods, 2018, 2, 1700230.

7 W. Xu, Z. Jiang, Q. Yang, W. Huo, M. S. Javed, Y. Li, L. Huang, X. Gu and C. Hu, Nano Energy, 2018, 43, 168-176.

8 B. K. Deka, A. Hazarika, J. Kim, Y. Bin Park and H. W. Park, Int. J. Energy Res., 2017, 41, 1397-1411.

9 F. Wang, X. Wu, X. Yuan, Z. Liu, Y. Zhang, L. Fu, Y. Zhu, Q. Zhou, Y. Wu and W. Huang, Chem. Soc. Rev., 2017, 46, 6816.

10 M. Armand and J. M. Tarascon, Nature, 2008, 451, 652-657.

11 W. Chen, H. Yu, S. Y. Lee, T. Wei, J. Li and Z. Fan, Chem. Soc. Rev., 2018, 47, 2837-2872.

12 Y. Z. Zhang, Y. Wang, T. Cheng, W. Y. Lai, H. Pang and W. Huang, Chem. Soc. Rev., 2015, 44, 5181-5199.

13 X. Lin, H. Lou, W. Lu, F. Xu, R. Fu and D. Wu, Chin. Chem. Lett., 2018, 29, 633-636.

14 Z. Song, D. Zhu, L. Li, T. Chen, H. Duan, Z. Wang, Y. Lv, W. Xiong, M. Liu and L. Gan, J. Mater. Chem. A, 2019, 7, 1177-1186.

15 L.-F. Chen, Z.-H. Huang, H.-W. Liang, W.-T. Yao, Z.-Y. Yu and S.-H. Yu, Energy Environ. Sci., 2013, 6, 3331-3338.

16 W. Wei, X. Cui, W. Chen and D. G. Ivey, Chem. Soc. Rev., 2011, 40, 1697-1721.

17 S. Chen, J. Zhu, X. Wu, Q. Han and X. Wang, ACS Nano, 2010, 4, 2822-2830.

18 L. Yuan, B. Yao, B. Hu, K. Huo, W. Chen and J. Zhou, Energy Environ. Sci., 2013, 6, 470-476.

19 Z. Yang, J. Tian, Z. Yin, C. Cui, W. Qian and F. Wei, Carbon N. Y., 2019, 141, 467-480.

20 S. Sankar, H. Lee, H. Jung, A. Kim, A. T. A. Ahmed, A. I. Inamdar, H. Kim, S. Lee, H. Im and D. Young Kim, New J. Chem., 2017, 41, 13792-13797.

21 S. B. Singh, T. Kshetri, T. I. Singh, N. H. Kim and J. H. Lee, Chem. Eng. J., 2019, 359, 197-207.

22 Y. Wang, W. Zhou, Q. Kang, J. Chen, Y. Li, X. Feng, D. Wang, Y. Ma and W. Huang, ACS Appl. Mater. Interfaces, 2018, 10, 27001-27008.

23 R. Wang, M. Yao and Z. Niu, InfoMat, 2020, 2, 113-125.

24 T. Chen and L. Dai, J. Mater. Chem. A, 2014, 2, 10756.

25 Z. Yang, J. Deng, X. Chen, J. Ren and H. Peng, Angew. Chem., Int. Ed., 2013, 52, 13453-13457.

26 T. Chen, H. Peng, M. Durstock and L. Dai, Sci. Rep., 2015, 4, 3612 .

27 H. Wang, Q. Zhou, B. Yao, H. Ma, M. Zhang, C. Li and G. Shi, Adv. Mater. Interfaces, 2018, 5, 1701547.

28 H. Peng, L. Xiao, K. Sun, G. Ma, G. Wei and Z. Lei, J. Power Sources, 2019, 435, 226800.

29 X. Zhang, B. He, Y. Zhao and Q. Tang, J. Power Sources, 2018, 379, 60-67.

30 M. Y. Jen, Z. W. Hung and C. Y. Chun, J. Membr. Sci., 2008, 322, 74-80.

31 J. Saunier, F. Alloin, J. Y. Sanchez and L. Maniguet, J. Polym. Sci., Part B: Polym. Phys., 2004, 42, 2308-2317.

32 D. Karabelli, J. C. Leprêtre, F. Alloin and J. Y. Sanchez, Electrochim. Acta, 2011, 57, 98-103. 
33 M. A. Hashim, L. Sa'adu, M. Bin Baharuddin and K. A. Dasuki, J. Mater. Sci. Res., 2013, 3, 25-29.

34 Y. Yin, O. Yamada, Y. Suto, T. Mishima, K. Tanaka, H. Kita and K. Okamoto, J. Polym. Sci., Part A: Polym. Chem., 2005, 43, 1545-1553.

35 J. A. Elliott and S. J. Paddison, Phys. Chem. Chem. Phys., 2007, 9, 2602-2618.

36 P. Staiti and F. Lufrano, Electrochim. Acta, 2010, 55, 7436-7442.

37 J. Zhou, J. Cai, S. Cai, X. Zhou and A. N. Mansour, J. Power Sources, 2011, 196, 10479-10483.

38 A. K. Solarajan, V. Murugadoss and S. Angaiah, J. Appl. Polym. Sci., 2017, 134, 45177.

39 A. K. Solarajan, V. Murugadoss and S. Angaiah, Appl. Mater. Today, 2016, 5, 33-40.

40 V. Murugadoss, S. Arunachalam, V. Elayappan and S. Angaiah, Ionics, 2018, 24, 4071-4080.

41 A. Laforgue and L. Robitaille, ECS Trans., 2011, 35, 13-20.

42 A. Laforgue and L. Robitaille, J. Electrochem. Soc., 2012, 159, 929-936.

43 M. Kumar, A. Subramania and K. Balakrishnan, Electrochim. Acta, 2014, 149, 152-158.

44 B. T. Weili Li, Y. Xing, Y. Wu, J. Wang, L. Chen and G. Yang, Electrochim. Acta, 2016, 151, 289-296.

45 K. Tõnurist, T. Thomberg, A. Jänes and E. Lust, J. Electrochem. Soc., 2013, 160, 449-457.

46 K. Tõnurist, A. Jänes, T. Thomberg, H. Kurig and E. Lust, J. Electrochem. Soc., 2009, 156, A334-A342.

47 K. Tõnurist, T. Thomberg, A. Jänes, T. Romann, V. Sammelselg and E. Lust, J. Electroanal. Chem., 2013, 689, 8-20.

48 R. Arthi, V. Jaikumar and P. Muralidharan, Energy Sources, Part A, 2019, 1-15.

49 T. He, R. Jia, X. Lang, X. Wu and Y. Wang, J. Electrochem. Soc., 2017, 164, E379-E384.

50 T. He, Y. Fu, X. Meng, X. Yu and X. Wang, Electrochim. Acta, 2018, 282, 97-104.

51 Q. Xie, X. Huang, Y. Zhang, S. Wu and P. Zhao, Appl. Surf. Sci., 2018, 443, 412-420.

52 M. Mastragostino and F. Soavi, J. Power Sources, 2007, 174, 89-93.

53 X. Liu and P. G. Pickup, J. Power Sources, 2008, 176, 410-416.

54 Z. Yang, Y. Jia, Y. Niu, Z. Yong, K. Wu, C. Zhang, M. Zhu, Y. Zhang and Q. Li, Chem. Eng. J., 2020, 400, 125835.

55 R. Na, X. Zhang, P. Huo, Y. Du, G. Huo, K. Zhu and G. Wang, High Perform. Polym., 2017, 29, 984-993.

56 E. Vargun, K. Ozaltin, H. Fei, E. Harea, J. Vilčáková, N. Kazantseva and P. Saha, J. Appl. Polym. Sci., 2020, 137, 49270.

57 D. Xu, G. Teng, Y. Heng, Z. Chen and D. Hu, Mater. Chem. Phys., 2020, 249, 122979.

58 G. Teng, S. Lin, D. Xu, Y. Heng and D. Hu, J. Mater. Sci.: Mater. Electron., 2020, 31, 7916-7926.

59 D. Zhao, C. Chen, Q. Zhang, W. Chen, S. Liu, Q. Wang, Y. Liu, J. Li and H. Yu, Adv. Energy Mater., 2017, 7, DOI: 10.1002/aenm.201700739.
60 H. Zhang, C.-E. Lin, M.-Y. Zhou, A. E. John and B.-K. Zhu, Electrochim. Acta, 2016, 187, 125-133.

61 B. Szubzda, A. Szmaja, M. Ozimek and S. Mazurkiewicz, Appl. Phys. A: Mater. Sci. Process., 2014, 117, 1801-1809.

62 E. Feng, G. Ma, K. Sun, Q. Yang, H. Peng and Z. Lei, RSC Adv., 2016, 6, 75896-75904.

63 Y. Zhong, X. Zhang, Y. He, H. Peng, G. Wang and G. Xin, Adv. Funct. Mater., 2018, 28, 1801998.

64 H. Peng, Y. Zhong, X. Zhang, Y. He and G. Wang, Langmuir, 2018, 34, 15245-15252.

65 X. Liu, D. Li, X. Chen, W. Y. Lai and W. Huang, ACS Appl. Mater. Interfaces, 2018, 10, 32536-32542.

66 E. Feng, G. Ma, K. Sun, F. Ran, H. Peng and Z. Lei, New J. Chem., 2017, 41, 1986-1992.

67 G. Ma, J. Li, K. Sun, H. Peng, J. Mu and Z. Lei, J. Power Sources, 2014, 256, 281-287.

68 J. Chen, W. Xiao, T. Hu, P. Chen, T. Lan, P. Li, Y. Li, B. Mi and Y. Ma, ACS Appl. Mater. Interfaces, 2020, 12, 5885-5891.

69 D. Boonpakdee, C. F. Guajardo Yévenes, W. Surareungchai and C. La-O-Vorakiat, J. Mater. Chem. A, 2018, 6, 7162-7167.

70 W. Li, X. Li, X. Zhang, J. Wu, X. Tian, M.-J. Zeng, J. Qu and Z.-Z. Yu, ACS Appl. Energy Mater., 2020, 3, 9408-9416.

71 J. Han, H. Wang, Y. Yue, C. Mei, J. Chen, C. Huang, Q. Wu and X. Xu, Carbon N. Y., 2019, 149, 1-18.

72 H. H. Hsu, Y. Liu, Y. Wang, B. Li, G. Luo, M. Xing and W. Zhong, ACS Sustainable Chem. Eng., 2020, 8, 6935-6948.

73 P. Tang, L. Han, P. Li, Z. Jia, K. Wang, H. Zhang, H. Tan, T. Guo and X. Lu, ACS Appl. Mater. Interfaces, 2019, 11, 7703-7714.

74 H. Yu, N. Rouelle, A. Qiu, J.-A. Oh, D. M. Kempaiah, J. D. Whittle, M. Aakyiir, W. Xing and J. Ma, ACS Appl. Mater. Interfaces, 2020, 12, 37977-37985.

75 Z. Pei, Z. Yuan, C. Wang, S. Zhao, J. Fei, L. Wei, J. Chen, C. Wang, R. Qi, Z. Liu and Y. Chen, Angew. Chem., Int. Ed., 2020, 59, 4793-4799.

76 J. W. Kim, H. Park, G. Lee, Y. R. Jeong, S. Y. Hong, K. Keum, J. Yoon, M. S. Kim and J. S. Ha, Adv. Funct. Mater., 2019, 29, 1905968.

77 L. Li, F. Lu, C. Wang, F. Zhang, W. Liang, S. Kuga, Z. Dong, Y. Zhao, Y. Huang and M. Wu, J. Mater. Chem. A, 2018, 6, 24468-24478.

78 H. Grebel and A. Patel, Chem. Phys. Lett., 2015, 640, 36-39.

79 J. Grebel, A. Banerjee and H. Grebel, Electrochim. Acta, 2013, 95, 308-312.

80 T. S. Chowdhury and H. Grebel, Electrochim. Acta, 2019, 307, 459-464.

81 W. G. Pell and B. E. Conway, J. Power Sources, 2004, 136, 334-345.

82 T. S. Chowdhury and H. Grebel, ChemEngineering, 2019, 3, 39.

83 C. Y. Bon, L. Mohammed, S. Kim, M. Manasi, P. Isheunesu, K. S. Lee and J. M. Ko, J. Ind. Eng. Chem., 2018, 68, 173-179.

84 M. Liu, K. Turcheniuk, W. Fu, Y. Yang, M. Liu and G. Yushin, Nano Energy, 2020, 71, 104627.

85 S. H. Ko, J. Chung, H. Pan, C. P. Grigoropoulos and D. Poulikakos, Sens. Actuators, A, 2007, 134, 161-168. 
86 J. Hao, W. Si, X. X. Xi, R. Guo, A. S. Bhalla and L. E. Cross, Appl. Phys. Lett., 2000, 76, 3100-3102.

87 C. O. Alvarez-sanchez, R. Massó-ferret and E. Nicolau, Energy Sci. Eng., 2019, 7, 730-740.

88 M. M. Ghobad Behzadi Pour and L. Fekri Aval, J. Mater. Sci. Mater. Electron., 2018, 29, 17432-17437.

89 H. H. Y. Jen Yu Shieh, S.-Y. Tsai and B.-Y. Li, Mater. Chem. Phys., 2017, 195, 114-122.

90 P. Sivaraman, S. P. Mishra, D. D. Potphode, A. P. Thakur, K. Shashidhara, A. B. Samui and A. R. Bhattacharyya, RSC $A d v .$, 2015, 5, 83546-83557.

91 C.-H. Chang, B. Hsia, J. P. Alper, S. Wang, L. E. Luna, C. Carraro, S.-Y. Lu and R. Maboudian, ACS Appl. Mater. Interfaces, 2015, 7, 26658-26665.

92 R. Na, P. Huo, X. Zhang, S. Zhang, Y. Du, K. Zhu, Y. Lu, M. Zhang, J. Luan and G. Wang, RSC Adv., 2016, 6, 65186-65195.

93 S. Mo, P. Lu, F. Ding, Z. Xu, J. Liu, X. Liu and Q. Xu, Solid State Ionics, 2016, 296, 37-41.

94 Z. Pang, J. Duan, Y. Zhao, Q. Tang, B. He and L. Yu, J. Power Sources, 2018, 400, 126-134.

95 S. Zheng, W. Lei, J. Qin, Z.-S. Wu, F. Zhou, S. Wang, X. Shi, C. Sun, Y. Chen and X. Bao, Energy Storage Mater., 2018, 10, 24-31.

96 H. Lee, M. Yanilmaz, O. Toprakci, K. Fu and X. Zhang, Energy Environ. Sci., 2014, 7, 3857-3886.

97 C. González, J. J. Vilatela, J. M. Molina-Aldareguía, C. S. Lopes and J. LLorca, Prog. Mater. Sci., 2017, 89, 194-251.

98 D. J. O'Brien, D. M. Baechle and E. D. Wetzel, J. Compos. Mater., 2011, 45, 2797-2809.

99 L. H. Acauan, Y. Zhou, E. Kalfon-Cohen, N. K. Fritz and B. L. Wardle, Nanoscale, 2019, 11, 21964-21973.

100 Q. Yao, H. Wang, C. Wang, C. Jin and Q. Sun, ACS Sustainable Chem. Eng., 2018, 6, 4695-4704.

101 N. Guo, M. Li, Y. Wang, X. Sun, F. Wang and R. Yang, ACS Appl. Mater. Interfaces, 2016, 8, 33626-33634.

102 J. Chen, X. Zhou, C. Mei, J. Xu, S. Zhou and C. P. Wong, J. Power Sources, 2017, 342, 48-55.

103 L. Jin, K. Wei, Y. Xia, B. Liu, K. Zhang, H. Gao, X. Chu, M. Ye, L. He and P. Lin, Mater. Today Energy, 2019, 14, 100348.

104 N. Liang, Y. Ji, D. Zuo, H. Zhang and J. Xu, Polym. Int., 2019, 68, 120-124.

105 F. Poli, D. Momodu, G. E. Spina, A. Terella, B. K. Mutuma, M. L. Focarete, N. Manyala and F. Soavi, Electrochim. Acta, 2020, 338, 135872.

106 D. Yang, L. Qi and J. Ma, Adv. Mater., 2002, 14, 1543-1546.

107 E. Taer, Sugianto, M. A. Sumantre, R. Taslim, Iwantono, D. Dahlan and M. Deraman, Adv. Mater. Res., 2014, 896, 66-69.

108 D. Dahlan, N. Sartika, Astuti, E. L. Namigo and E. Taer, Mater. Sci. Forum, 2015, 827, 151-155.

109 H. Yu, Q. Tang, J. Wu, Y. Lin, L. Fan, M. Huang, J. Lin, Y. Li and F. Yu, J. Power Sources, 2012, 206, 463-468.

110 Y. Zhang, J. He, Z. Gao and X. Li, Nano Energy, 2019, 65, 104045.
111 P. Yang, J. Xie and C. Zhong, ACS Appl. Energy Mater., 2018, 1, 616-622.

112 Y. Zhao, S. Huang, M. Xia, S. Rehman, S. Mu, Z. Kou, Z. Zhang, Z. Chen, F. Gao and Y. Hou, Nano Energy, 2016, 28, 346-355.

113 D. Hulicova, J. Yamashita, Y. Soneda, H. Hatori and M. Kodama, Chem. Mater., 2005, 17, 1241-1247.

114 K. Torvinen, S. Lehtimäki, J. T. Keränen, J. Sievänen, J. Vartiainen, E. Hellén, D. Lupo and S. Tuukkanen, Electron. Mater. Lett., 2015, 11, 1040-1047.

115 Y. S. Yang, I.-K. You, S.-H. Hong and H.-G. Yun, Electrochem. Soc., 2014, 64, 135-137.

116 M. Arvani, J. Keskinen, A. Railanmaa, S. Siljander, T. Björkqvist, S. Tuukkanen and D. Lupo, J. Appl. Electrochem., 2020, 50, 689-697.

117 I. Sakurada, Y. Nukushina and T. Ito, J. Polym. Sci., 1962, 57, 651-660.

118 D. Lasrado, S. Ahankari and K. Kar, J. Appl. Polym. Sci., 2020, 137, 48959.

119 Q. Zhang, C. Chen, W. Chen, G. Pastel, X. Guo, S. Liu, Q. Wang, Y. Liu, J. Li, H. Yu and L. Hu, ACS Appl. Mater. Interfaces, 2019, 11, 5919-5927.

120 K. K. Liu, Q. Jiang, C. Kacica, H. G. Derami, P. Biswas and S. Singamaneni, RSC Adv., 2018, 8, 31296-31302.

121 X. Lv, G. Li, D. Li, F. Huang, W. Liu and Q. Wei, J. Phys. Chem. Solids, 2017, 110, 202-210.

122 C. Tang, Z. Tang and H. Gong, J. Electrochem. Soc., 2012, 159, A651-A656.

123 C. X. Guo, A. A. Chitre and X. Lu, Phys. Chem. Chem. Phys., 2014, 16, 4672.

124 R. R. Salunkhe, J. Tang, Y. Kamachi, T. Nakato, J. H. Kim and Y. Yamauchi, ACS Nano, 2015, 9, 6288-6296.

125 Y.-T. Wang, A.-H. Lu, H.-L. Zhang and W.-C. Li, J. Phys. Chem. C, 2011, 115, 5413-5421.

126 M. Huang, Y. Zhang, F. Li, L. Zhang, Z. Wen and Q. Liu, J. Power Sources, 2014, 252, 98-106.

127 W. Liu, X. Li, M. Zhu and X. He, J. Power Sources, 2015, 282, 179-186.

128 S. Wu, W. Chen and L. Yan, J. Mater. Chem. A, 2014, 2, 2765.

129 Y. Li, J. Xu, T. Feng, Q. Yao, J. Xie and H. Xia, Adv. Funct. Mater., 2017, 27, 1606728.

130 C. G. Cameron and S. M. Fitzsimmons, Supercapacitor separators and polypyrrole composites, defence $R \& D$ Canada-Atlantic, 2008.

131 J. Cai, S. Liu, J. Feng, S. Kimura, M. Wada, S. Kuga and L. Zhang, Angew. Chem., Int. Ed., 2012, 51, 2076-2079.

132 L. Hu, W. Chen, X. Xie, N. Liu, Y. Yang, H. Wu, Y. Yao, M. Pasta, H. N. Alshareef and Y. Cui, ACS Nano, 2011, 5, 8904-8913.

133 H. Koga, H. Tonomura, M. Nogi, K. Suganuma and Y. Nishina, Green Chem., 2016, 18, 1117-1124.

134 P. Tammela, H. Olson, M. Strømme and L. Nyholm, J. Power Sources, 2014, 272, 468-475.

135 L. Hu, H. Wu and Y. Cui, Appl. Phys. Lett., 2010, 96, 183502.

136 I. Bispo-Fonseca, J. Aggar, C. Sarrazin, P. Simon and J. F. Fauvarque, J. Power Sources, 1999, 79, 238-241. 
137 A. M. Bittner, M. Zhu, Y. Yang, H. F. Waibel, M. Konuma, U. Starke and C. J. Weber, J. Power Sources, 2012, 203, 262-273.

138 I. Jung, D. A. Dikin, R. D. Piner and R. S. Ruoff, Nano Lett., 2008, 8, 4283-4287.

139 J. H. Sluyters and M. Sluyters-Rehbach, J. Phys. Chem. B, 2010, 114, 15582-15589.

140 Y. M. Shulga, S. A. Baskakov, V. A. Smirnov, N. Y. Shulga, K. G. Belay and G. L. Gutsev, J. Power Sources, 2014, 245, 33-36.

141 S. Baskakov, Y. V. Baskakova, N. V. Lyskov, N. N. Dremova, A. V. Irzhak, Y. Kumar, A. Michtchenok and Y. Shulga, Electrochim. Acta, 2018, 260, 557-563.

142 Y. M. Shulga, S. A. Baskakov, Y. V. Baskakova, Y. M. Volfkovich, N. Y. Shulga, E. A. Skryleva, Y. N. Parkhomenko, K. G. Belay, G. L. Gutsev, A. Y. Rychagov, V. E. Sosenkin and I. D. Kovalev, J. Power Sources, 2015, 279, 722-730.

143 H. Gao, H. Shen, H. Wu, H. Jing, Y. Sun, B. Liu, Z. Chen, J. Song, L. Lu, Z. Wu and Q. Hao, Energy Fuels, 2021, 35, 12884-12901.

144 J. Cai, Y. Song, X. Chen, Z. Sun, Y. Yi, J. Sun and Q. Zhang, J. Mater. Chem. A, 2020, 8, 1757-1766.

145 A. E. Baumann, D. A. Burns, B. Liu and V. S. Thoi, Chem. Commun., 2019, 2, 86.

146 S. Suriyakumar, A. M. Stephan, N. Angulakshmi, M. H. Hassan and M. H. Alkordi, J. Mater. Chem. A, 2018, 6, 14623-14632.

147 J.-P. Meng, Y. Gong, Q. Lin, M.-M. Zhang, P. Zhang, H.-F. Shi and J.-H. Lin, Dalton Trans., 2015, 44, 5407-5416.

148 W. Nie, S. Zhang, X. Ding, J. Hu, X. Yang and Q. Li, Text. Res. J., 2019, 89, 4265-4271.

149 Y. Lu, Y. Jiang, Z. Lou, R. Shi, D. Chen and G. Shen, Prog. Nat. Sci. Mater. Int., 2020, 30, 174-179.

150 M. F. M. Yaacob, Z. A. Noorden and J. J. Jamian, PECON 2016-2016 IEEE 6th Int. Conf. Power Energy, Conf. Proceeding, 2017, pp. 718-722.

151 R. Kötz and M. Carlen, Electrochim. Acta, 2000, 45, 2483-2498.

152 P. Arora and Z. Zhang, Chem. Rev., 2004, 104, 4419-4462.

153 A. Yu, V. Chabot and J. Zhang, Electrochemical Supercapacitors for Energy Storage and Delivery: Fundamentals and Applications, CRC Press, 1st edn, 2013.

154 L. Dong, C. Xu, Y. Li, Z. H. Huang, F. Kang, Q. H. Yang and X. Zhao, J. Mater. Chem. A, 2016, 4, 4659-4685.

155 L. Zhang, D. Liu, Z. S. Wu and W. Lei, Energy Storage Mater., 2020, 32, 402-417.

156 J. Qin, P. Das, S. Zheng and Z. S. Wu, APL Mater., 2019, 7, 090902.

157 Q. Zhang, L. Liu, C. Pan and D. Li, J. Mater. Sci., 2018, 53, 27-46.

158 L. Li, F. Lu, C. Wang, F. Zhang, W. Liang, S. Kuga, Z. Dong, Y. Zhao, Y. Huang and M. Wu, J. Mater. Chem. A, 2018, 6, 24468-24478.

159 B. Xie, C. Yang, Z. Zhang, P. Zou, Z. Lin, G. Shi, Q. Yang, F. Kang and C. P. Wong, ACS Nano, 2015, 9, 5636-5645.

160 J. Gao, C. Shao, S. Shao, C. Bai, U. R. Khalil, Y. Zhao, L. Jiang and L. Qu, ACS Nano, 2019, 13, 7463-7470.
161 Y. Yan, J. Yan, X. Gong, X. Tang, X. Xu, T. Meng, F. Bu, D. Cai, Z. Zhang, G. Nie and H. Zhang, Chem. Eng. J., 2021, 133580.

162 W. Gao, L. B. Alemany, L. Ci and P. M. Ajayan, Nat. Chem., 2009, 1, 403-408.

163 S. Cerveny, F. Barroso-Bujans, Á. Alegría and J. Colmenero, J. Phys. Chem. C, 2010, 114, 2604-2612.

164 W. Gao, N. Singh, L. Song, Z. Liu, A. L. M. Reddy, L. Ci, R. Vajtai, Q. Zhang, B. Wei and P. M. Ajayan, Nat. Nanotechnol., 2011, 6, 496-500.

165 A. Maitra, S. K. Karan, S. Paria, A. K. Das, R. Bera, L. Halder, S. K. Si, A. Bera and B. B. Khatua, Nano Energy, 2017, 40, 633-645.

166 H. Guo, M.-H. Yeh, Y.-C. Lai, Y. Zi, C. Wu, Z. Wen, C. Hu and Z. L. Wang, ACS Nano, 2016, 10, 10580-10588.

167 A. Ramadoss, B. Saravanakumar, S. W. Lee, Y. S. Kim, S. J. Kim and Z. L. Wang, ACS Nano, 2015, 9, 4337-4345.

168 L. Xing, Y. Nie, X. Xue and Y. Zhang, Nano Energy, 2014, 10, 44-52.

169 R. Song, H. Jin, X. Li, L. Fei, Y. Zhao, H. Huang, H. Lai-Wa Chan, Y. Wang and Y. Chai, J. Mater. Chem. A, 2015, 3, 14963-14970.

170 T. Chen, R. Hao, H. Peng and L. Dai, Angew. Chem., Int. Ed., 2015, 54, 618-622.

171 L. Liu, Y. Yu, C. Yan, K. Li and Z. Zheng, Nat. Commun., 2015, 6, 7260.

172 Q. Huang, D. Wang and Z. Zheng, Adv. Energy Mater., 2016, 6, 1600783.

173 Y. Kang, H. J. Kim, E. Kim, B. Oh and J. H. Cho, J. Power Sources, 2001, 92, 255-259.

174 Z. Gui, H. Zhu, E. Gillette, X. Han, G. W. Rubloff, L. Hu and S. B. Lee, ACS Nano, 2013, 7, 6037-6046.

175 P. Azaïs, L. Duclaux, P. Florian, D. Massiot, M. A. LilloRodenas, A. Linares-Solano, J. P. Peres, C. Jehoulet and F. Béguin, J. Power Sources, 2007, 171, 1046-1053.

176 T. Hibino, K. Kobayashi, M. Nagao and S. Kawasaki, Sci. Rep., 2015, 5, 7903.

177 B. Asbani, C. Douard, T. Brousse and J. Le Bideau, Energy Storage Mater., 2019, 21, 439-445.

178 M. Ouyang, D. Ren, L. Lu, J. Li, X. Feng, X. Han and G. Liu, J. Power Sources, 2015, 279, 626-635.

179 R. Kötz, P. W. Ruch and D. Cericola, J. Power Sources, 2010, 195, 923-928.

180 Y. Shi, H. Ha, A. Al-Sudani, C. J. Ellison and G. Yu, Adv. Mater., 2016, 28, 7921-7928.

181 H. Yang, Z. Liu, B. K. Chandran, J. Deng, J. Yu, D. Qi, W. Li, Y. Tang, C. Zhang and X. Chen, Adv. Mater., 2015, 27, 5593-5598.

182 P. Zhang, J. Wang, W. Sheng, F. Wang, J. Zhang, F. Zhu, X. Zhuang, R. Jordan, O. G. Schmidt and X. Feng, Energy Environ. Sci., 2018, 11, 1717-1722.

183 M. A. C. Stuart, W. T. S. Huck, J. Genzer, M. Müller, C. Ober, M. Stamm, G. B. Sukhorukov, I. Szleifer, V. V. Tsukruk, M. Urban, F. Winnik, S. Zauscher, I. Luzinov and S. Minko, Nat. Mater., 2010, 9, 101-113.

184 H. Jiang, R. K. Emmett and M. E. Roberts, J. Appl. Electrochem., 2019, 49, 271-280. 
185 M. Inagaki, H. Konno and O. Tanaike, J. Power Sources, 2010, 195, 7880-7903.

186 Y. Soneda, M. Toyoda, Y. Tani, J. Yamashita, M. Kodama, H. Hatori and M. Inagaki, J. Phys. Chem. Solids, 2004, 65, 219-222.

187 T. W. Weng, W. Huang and K. Y. Lee, Vacuum, 2008, 83, 629-632.

188 R. Kötz and M. Carlen, Electrochim. Acta, 2000, 45, 2483-2498.

189 Z. A. Noorden, S. Sugawara and S. Matsumoto, IEEJ Trans. Electr. Electron. Eng., 2014, 9, 235-240.

190 Z. A. Noorden, S. Sugawara and S. Matsumoto, ECS Trans., 2013, 53, 43-51.
191 A. Lewandowski, A. Olejniczak, M. Galinski and I. Stepniak, J. Power Sources, 2010, 195, 5814-5819.

192 K. Liivand, T. Thomberg, A. Jänes and E. Lust, ECS Trans., 2015, 64, 41-49.

193 M. Kaus, J. Kowal and D. U. Sauer, Electrochim. Acta, 2010, 55, 7516-7523.

194 A. Lewandowski, P. Jakobczyk, M. Galinski and M. Biegun, Phys. Chem. Chem. Phys., 2013, 15, 8692-8699.

195 T. Tevi and A. Takshi, J. Power Sources, 2015, 273, 857-862.

196 T. Xiong, Z. G. Yu, W. S. V. Lee and J. Xue, ChemSusChem, 2018, 11, 3307-3314.

197 H.-S. Dang, E. A. Weiber and P. Jannasch, J. Mater. Chem. A, 2015, 3, 5280-5284. 